Tethys, 6, 31-50, 2009

Journal of Weather \& Climate of the Western Mediterranean

www.tethys.cat

ISSN-1697-1523

eISSN-1139-3394

DOI:10.3369/tethys.2009.6.03

\title{
Pluviometric anomaly in the Llobregat Delta
}

\author{
J. Mazón ${ }^{1}$ and D. Pino ${ }^{1,2}$ \\ ${ }^{1}$ Department of Applied Physics. Escola Politècnica Superior de Castelldefels, Universitat Politècnica de Catalunya. Avda. \\ del Canal Olímpic s/n. 08860 Castelldefels \\ ${ }^{2}$ Institut d'Estudis Espacials de Catalunya (IEEC/CSIC). Barcelona
}

Received: 16-X-2008 - Accepted: 10-III-2009 - Translated version

Correspondence to: Jordi.Mazon@upc.edu

\begin{abstract}
The data from surface automatic weather stations show that in the area of the Llobregat delta (northeast of the Iberian Peninsula) we can observe greater precipitation than in nearby inland areas (Ordal, Collserola, Garraf), than on the other side of a massif located on the coast (Garraf) and than on the northern coast. This distribution of the precipitation could be explained by the formation of a nocturnal surface cold front in the Llobregat delta. In order to analyze in-depth the physical mechanisms that can influence the formation of this front (topography, sea and drainage winds), two rain episodes in the area were simulated with the MM5 mesoscale model, reproducing satisfactorily the physical mechanisms that favor the appearance of the front.
\end{abstract}

Key words: nocturnal land breeze, coastal fronts, precipitation rhythms

\section{Introduction}

When two air masses with different temperatures, and therefore different densities, converge on the surface, as it is known, they do not mix, but the warmer and less dense mass moves above the cold one. If the cold mass, which is more dense, is the one that advances under the warm one, the result is the formation of a cold front. If the warm mass moves above the cold one, the result is the formation of a warm front. When ascending, the relatively warm mass gets cooler and might therefore generate cloudiness and precipitation.

As we will see, the comparative climatic analysis of the precipitation in the Llobregat delta and neighboring areas indicates that precipitation is greater in the delta than in the neighboring areas from the end of the summer to the beginning of the winter, but above all during the fall. The reason for this pluviometric anomaly, as proposed in this work, is the formation of a nocturnal surface cold front over the delta, or at a few kilometers from the coast.

The topographic characteristics of the Llobregat delta would favor the convergence of air masses of different densities. First of all, this is because of the existence of the wide and long low-lying valley of the Llobregat river, confined between the Ordal and Collserola ranges in its last stretch, which becomes wider when reaching the delta area. Secondly, it is due to the sudden rise of the Garraf massif, in the westernmost area of the delta, and of Montjuïc Mountain to the east, both limiting the Llobregat delta, and therefore limiting the cold air that descends the valley during the night. Lastly, there is the presence of the Mediterranean sea, with high water temperatures from the end of the summer until the beginning of the winter, which guarantee a warm and moist air mass in the coastal region.

This work is structured as follows: Section 2 explains how a coastal front is formed through differences of temperature between air masses. Section 3 is dedicated to the climatic analysis of the area. Once the pluviometric peculiarity of this area is detected and explained, Section 4 explains the modeling of two rain episodes in the area with the mesoscale model MM5 (Dudhia, 1993). The article ends with the conclusions.

\section{The surface cold front}

The formation of a coastal surface cold front through the interaction of a relatively cold air mass, that descends a valley (drainage) or comes from the mountains located near 


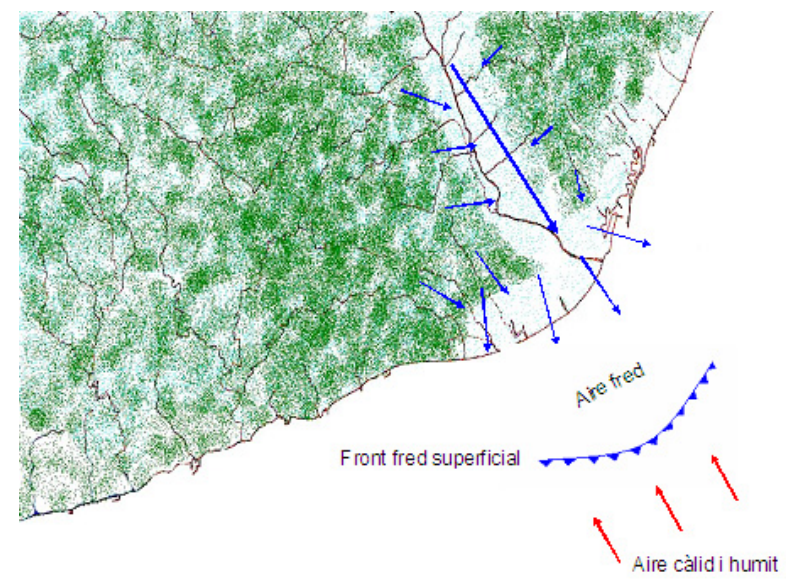

Figure 1. Sketch of the surface front formation in the area of the Llobregat delta.

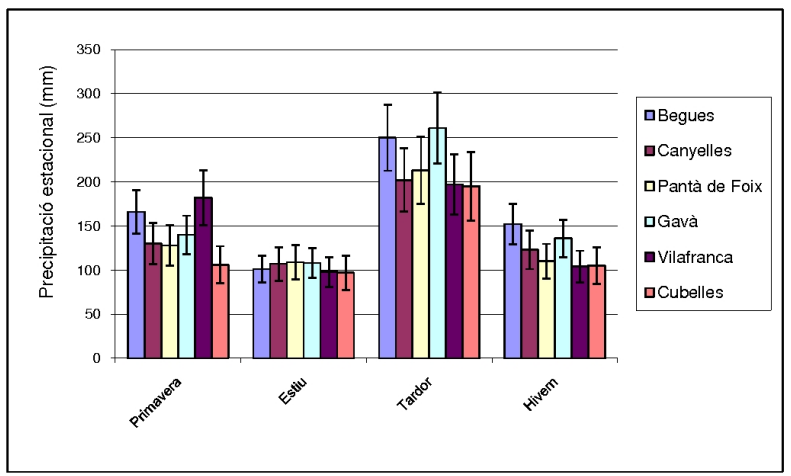

Figure 2. Seasonal distribution of precipitation in the observatories of Figure 3 during the period 1978-2002.

the coast, with a warmer and moister air mass has been studied by different authors (Neumann, 1951; Zhong and Takle, 1992; Koch and Ray, 1997; Callado and Pascual, 2002; Malda et al., 2007).

In the particular case of the northeast coast of the Iberian Peninsula, during the nights at the end of the summer, and above all in the fall, the cooling of the surface air in the pre-coastal area, corresponding to the annual cycle of ground temperature, begins to be significant, and it flows towards the coast. According to Callado and Pascual (2002) this induces convergence that might cause storms. Different episodes of convective storms were analyzed in that work associated to air draining in the valleys of four rivers of the Catalan coast: Ebre, Francolí, Llobregat and Besòs. The formation of a front, which does not necessarily create a convective storm, would be favored in the Llobregat delta due to its particular topographic characteristics: there is a long valley in its final stretch, with no meanders. In this case, the air from the mountains of the Ordal and Collserola flows into the low valley and can drain freely towards the delta. This relatively cold air that descends the Llobregat valley and has a depth of approximately $100 \mathrm{~m}$ (Callado and Pascual, 2002), expands when it arrives to the delta, and creates a relatively cold air front when it comes into contact with the warm and moist Mediterranean air mass (Fontserè, 1959; Jansà, 1997; see Figure 1).

The expansion of the cold air when arriving to the Llobregat delta would be limited to the northeast by Montjuic Mountain and the plain of Barcelona, and to the west by the rising of the Garraf massif. Therefore, the superficial cold front can be generated over the delta, and it could advance out to sea or remain fairly stationary over the delta, depending on its characteristics (Figure 1). If, in addition to that, there is a flow inland (Callado and Pascual, 2002) the convergence between the surface cold front and the warm and moist mass of the Mediterranean becomes intensified, increasing upwards motion. On occasions, the unstable air could overcome the level of free convection, creating clouds of vertical development that could entail storms and intense rain that pour down near the convergence area, sometimes over the sea, sometimes over the delta, but hardly ever over the neighboring areas of the delta (see Figure 1).

An important factor for the front to produce precipitation is its height. Neumann (1951) proposes mechanisms such as the one described in this work to argue the high level of nocturnal pluviometry in some coastal areas of the eastern Mediterranean. In that work, despite the depth of the drainage current or of the nocturnal land breeze mentioned above, front heights between 1000 and $1500 \mathrm{~m}$ were indicated. These values were similar to those found for the Llobregat delta in a previous work (Herrero, 2008). As also indicated by Neumann (1951), Callado and Pascual (2002), Pascual and Callado (2002), precipitation generated by the above described mechanism usually happens at night. As we will see, in the case of the Llobregat delta this is clearly marked in the pluviometric register of one of the stations in the area.

\section{Observational evidence: climatic analysis of the precipitation}

The proposed pluviometric anomaly of the Llobregat delta was detected from the climatic analysis of monthly and yearly precipitation averages from several official observatories of the Agencia Estatal de Meteorología (Spanish meteorological agency). The instrument used to register the precipitation is the $200 \mathrm{~mm}$ Hellman manual rain gauge. The data was homogenized by the von Neumann test (von Neumann, 1941). Two temporal series were analyzed: monthly rainfall from 1978 to 2002, and a second series that includes more official observatories of this network, from 1996 to 2005. The results of this last series of data have no climatic validity, but they helped to finish outlining the tendency indicated by the first data series, with over a 27 year span, and, roughly speaking, climatic validity, as defined by the OMM, which requires statistics done in 30 year series. 


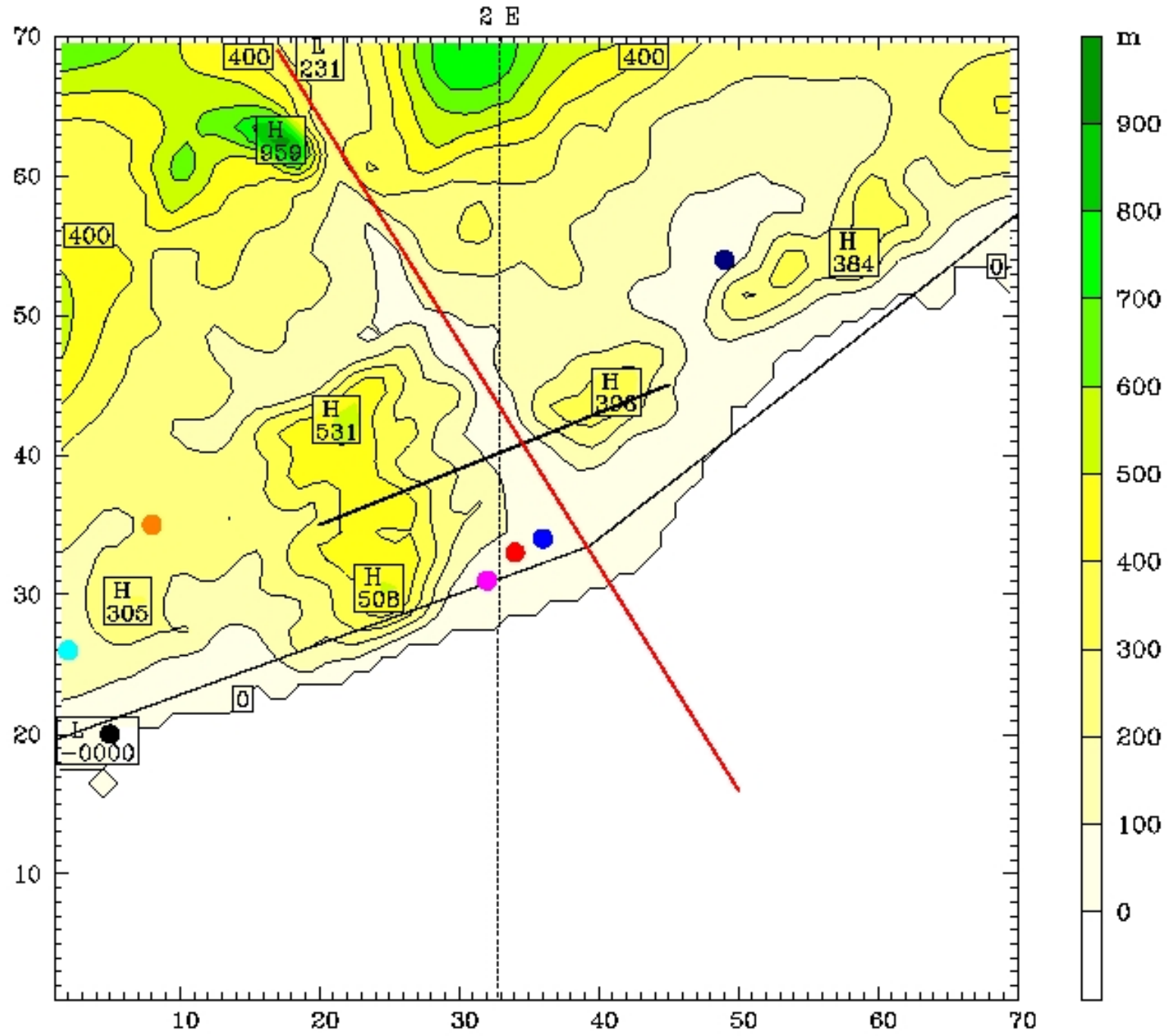

Figure 3. Geographical location of the analyzed stations: Gavà (purple), Vilafranca (orange), Foix reservoir (light blue), Cubelles (black), Canyelles (dark blue), Begues (blue), Viladecans (red). The lines show the cuts where wind pattern will be analized in the Llobregat valley and delta. The units in the axis are kilometers.

\subsection{Seasonal and annual precipitation}

Figure 2 shows the seasonal pluviometric regime of the analyzed observatories (Figure 3 represents the geographical location of the observatories). It can be observed that the qualitative pluviometric behavior of the analyzed observatories follows the typical regime of coastal Mediterranean climate (Bolle, 2002), with a pluviometric maximum in the fall, a secondary one in the spring, and two minimums, in the winter and the summer. The precipitation during each season and the fundamental mechanisms that can generate it are analyzed below.

As reflected in Figure 2, summer precipitation (from June to August) is almost homogeneous in relation with the environment. It is basically caused by storms, and although the precipitation is normally well localized, over the years they affect the surrounding area of the Llobregat delta in a similar way. Therefore, summer storms affect the different stations in the same way and there is no anomaly in the delta during this season.

Spring precipitation (from March to April) is caused, generally, by the passing of frontal systems associated with low pressures. The more north and inland these systems are located, the more active they are. For this reason, during this time of the year, it is in Vilafranca, located in an inland area (see Figure 3), where the precipitation presents a maximum with regard to other surrounding areas of the Garraf massif, especially in the Llobregat delta (stations of Gavà and Begues), where precipitation is significantly lower (see Figure 2).

In the fall (from September to November), precipitation in the analyzed period is notably higher in the Llobregat delta 

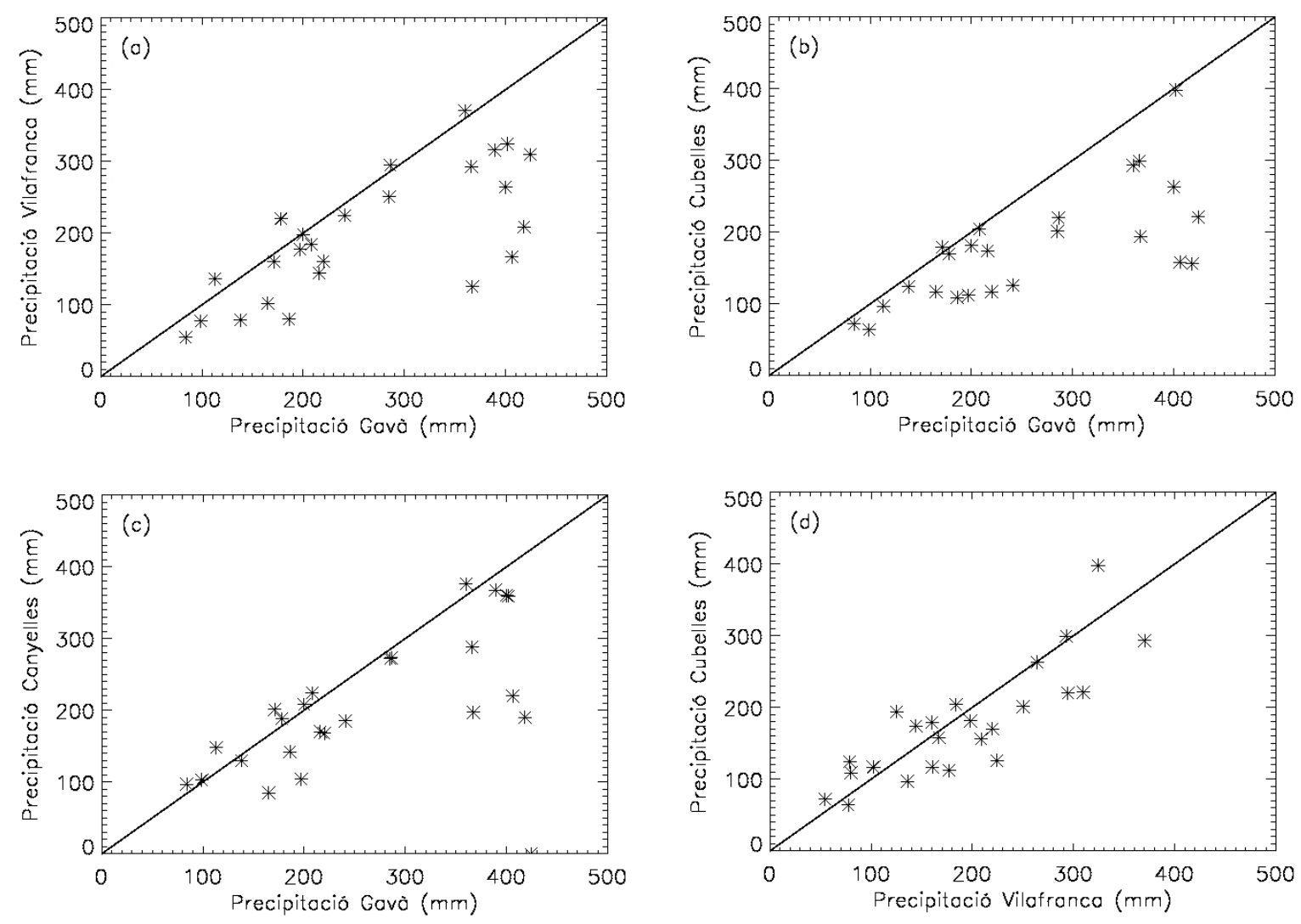

Figure 4. Comparison of pluviometry in the fall between different stations of the Llobregat delta and its environs during the period 19782002.

(Gavà and Begues stations from Figure 2) than in the Penedès plain (north of the Garraf massif, station of Vilafranca), and to the southwest of the massif (Cubelles). Likewise, except in the delta, fall precipitation does not present, in general terms, significant differences among other points in the mountain region. Figure 4 represents the comparison between the rain collected each year in the fall from 1978 to 2002 in the station of Gavà and in stations located to the south of the Garraf massif. It shows that between the north (Vilafranca) and the southwest (Cubelles) of the massif, precipitation is very similar. Only in the delta, and in the high plain of Begues, at an altitude of $400 \mathrm{~m}$, it presents values that are clearly higher than the others and can be compared among them.

The tendency in the differences of precipitation in the fall in the station of Gavà and the other stations shows a different behavior between the stations located to the north and to the south of the Llobregat. In the case of Canyelles (the northern point of Figure 3), the only station that presents a drop in precipitation over the years, there is an increase detected in the anomaly in the period studied (1978-2002). At the rest of the stations, the anomaly presented by the Llobregat delta remains approximately constant (Cubelles) or clearly decreases (Vilafranca, Begues and Foix reservoir). The reason is that in the former stations precipitation rises in the fall far more than in the station in Gavà. Although a more in-depth study of the tendencies is needed, including other stations, this data could be a first indicator that the significance of the Garraf massif as a separating element of the precipitation is decreasing with time.

In relation to precipitation in the winter (from December to February), everything seems to indicate that there is a slight positive tendency in the precipitation in the delta in relation to the observatories located on the other side of the Garraf massif, to the north, west and southwest of it. The reason could probably be that December is considered as winter, and the formation of the surface front in the delta is still possible more or less actively.

The difference in pluviometry in the fall conditions the annual variations of precipitation. Figure 5 shows the comparison between annual precipitation during the period 19782002 in different observatories located in the delta region and the pluviometric station of the delta, Gavà. From the figure we can conclude that the Garraf massif acts as a modifier of the precipitation between the east and the northeast side on the one hand, and, on the other, the west, north and southwest. It can be observed that there is more accumulated precipitation in the station located to the east of the massif (Gavà) each year than in the other stations. In the case of the 

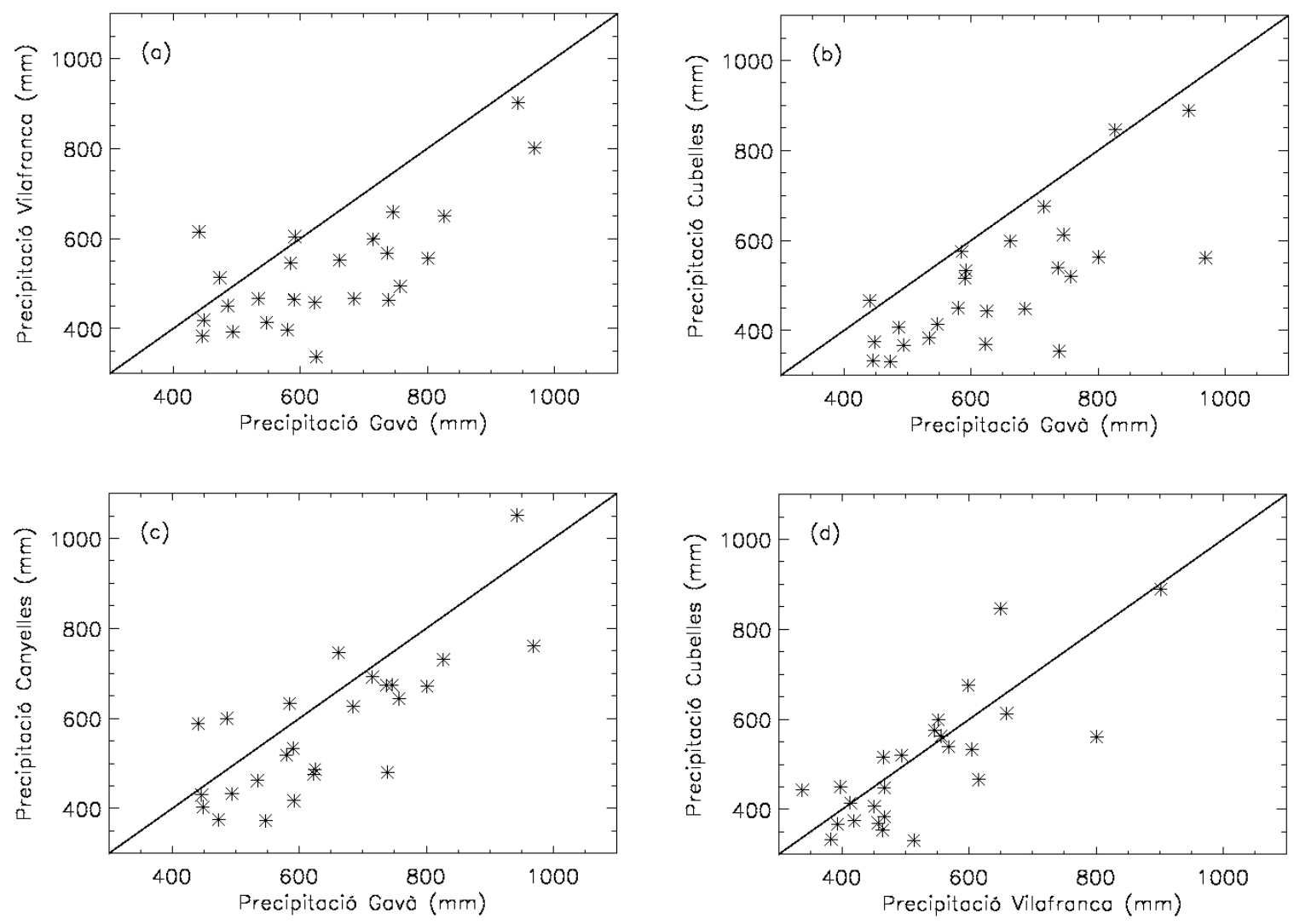

Figure 5. Comparison of annual pluviometry between the delta (Gavà) and other nearby stations out of the delta in the period 1978-2002.

stations located to the west of the Garraf massif, it is generally set out around the line of equiprecipitation. The excess of precipitation in Vilafranca in comparison with Cubelles (Figure 5d) can be explained, as mentioned earlier, by spring precipitation.

To complete the analysis, Figure 6, shows the isohyetal map resulting from the pluviometric analysis during the period 1996-2005. There is an unequal distribution of the precipitation in the environment of the Garraf massif, more annual precipitation is detected in the observatories located to the east of the massif, over $630 \mathrm{~mm}$ in Gavà and Begues. These values contrast with those collected in the observatories located to the west and north of the massif: Vilafranca, that is only $25 \mathrm{~km}$ away from Gavà, and $15 \mathrm{~km}$ from Begues, presents an annual precipitation that is notably slighter, clearly under $600 \mathrm{~mm}$. The annual average precipitation is $122 \mathrm{~mm}$ less in Sitges than in Gavà, with a distance of about $15 \mathrm{~km}$ between both observatories, separated by the Garraf massif. The Fabra observatory in Barcelona shows slightly less precipitation than in Gavà, although it is located at an altitude of $400 \mathrm{~m}$ above sea level, and therefore in an area where precipitation is more effective.

The pluviometric anomaly is also evident in the analysis of other variables related to the precipitation, such as the number of rainy days (days with more than $0.1 \mathrm{~mm}$ of precipitation). So, in the period from 1978-2002, there is a higher number of precipitation days in those observatories located to the east and northeast of the Garraf massif (Gavà and Begues, with 81 and 83 days respectively) in comparison with the others (Sitges, Canyelles, Vilafranca, with 73, 51 and 70 days respectively).

\subsection{Nocturnal precipitation}

Regarding the time of daily precipitation, hourly data from the automatic meteorological station of the Servei de Meteorologia de Catalunya (Meteorological Service of Catalonia) located in Viladecans was used, in the agricultural area of the delta. Daily precipitation at an hourly scale, from 1993 until the end of 2005, was analyzed; selecting those days when precipitation is between 22 UTC and 07 UTC.

It must be noted in first place that nocturnal precipitation in the month of September represents nearly all the precipitation occurring in this month in every year studied. Of the $68 \mathrm{~mm}$ of average precipitation, nearly $59 \mathrm{~mm}$ had fallen at night, between 22 UTC and 07 UTC; that is to say, it constitutes $87 \%$ of the total precipitation during this month. This is the month in which the surface frontal system is probably more active, and can generate more significant precipitation. 


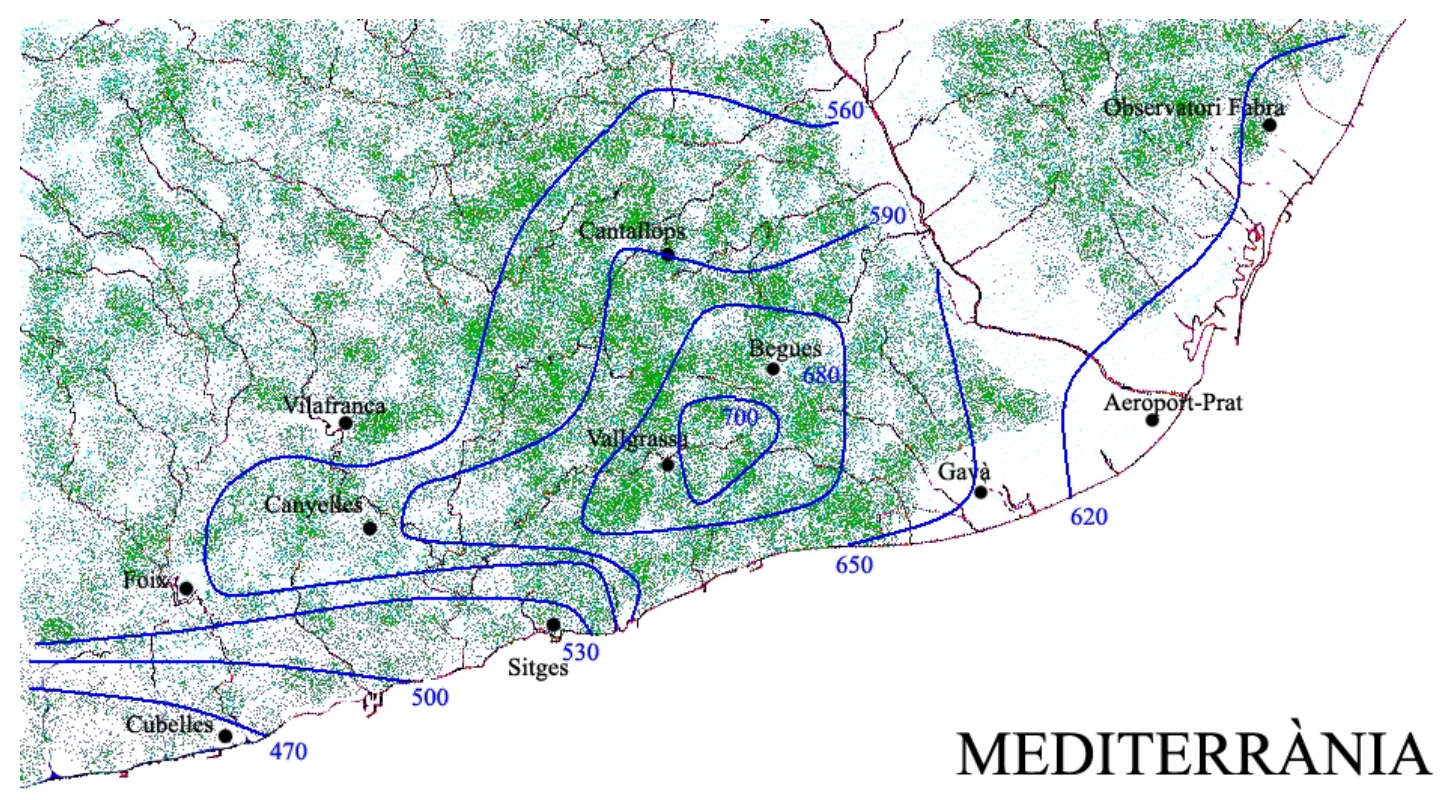

Figure 6. Isohyetal lines of annual precipitation (mm) during the period 1996-2005. The figure shows the stations used in the study.

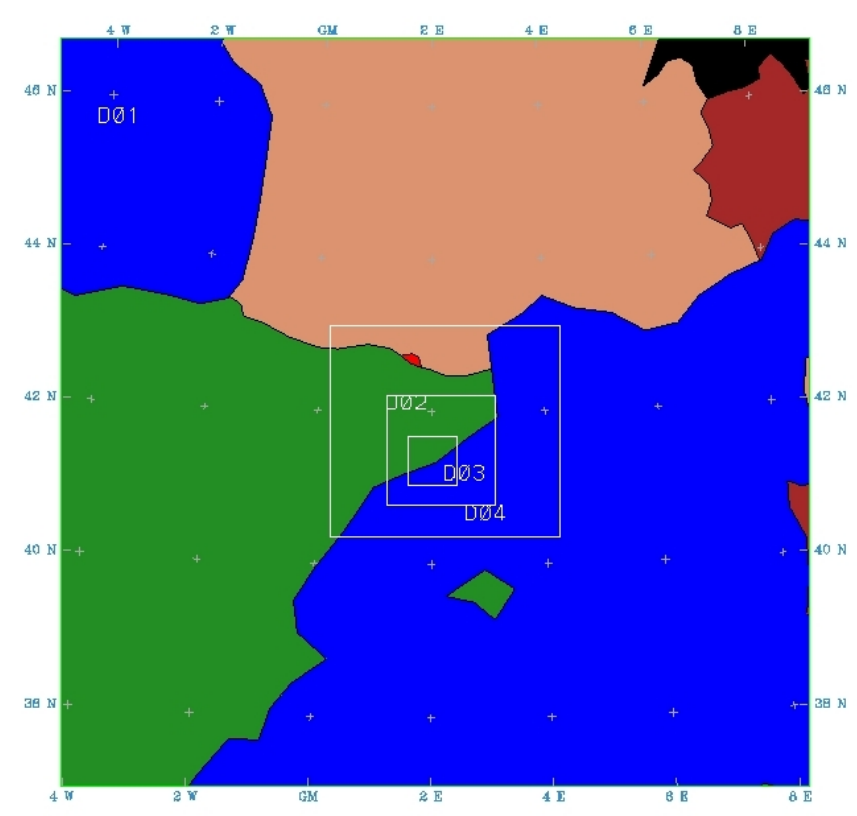

Figure 7. Domains of the simulation with the MM5 model.
In October, out of a total of $69 \mathrm{~mm}$ of average precipitation, nearly $44 \mathrm{~mm}$ fell during the nighttime, that is to say, $64 \%$. During the months of November, December and January, this percentage falls considerably when the formation of the surface front is more difficult, and in the event it occurs, it is less active. Therefore, as Neumann (1951) had already shown, the majority of the precipitation associated to this kind of situation is nocturnal.

From this analysis the existence of a pluviometric mechanism is observed, which leaves, in general terms, more precipitation in the delta than in the surrounding observatories. This precipitation occurs basically in the fall and it is nocturnal. This marked difference, and the season it happens in, raises the hypothesis of the formation of a surface cold front as a generating mechanism of greater precipitation in the Llobregat delta.

The results of the analysis of the pluviometric anomaly on an annual and seasonal level, are in agreement with some previous works, which denote a pluviometric maximum in the area of the Llobregat delta in relation to its closest surroundings (Clavero et al., 1996).

\section{Modeling of the nocturnal surface front}

Once the difference of precipitation between the Llobregat delta and other close-lying areas is analyzed, and how this could be explained by the formation of a nocturnal front in the area of the Llobregat delta, we will study in-depth some episodes of nocturnal precipitation that either almost exclusively affected the delta, or was intensified in this ge- 


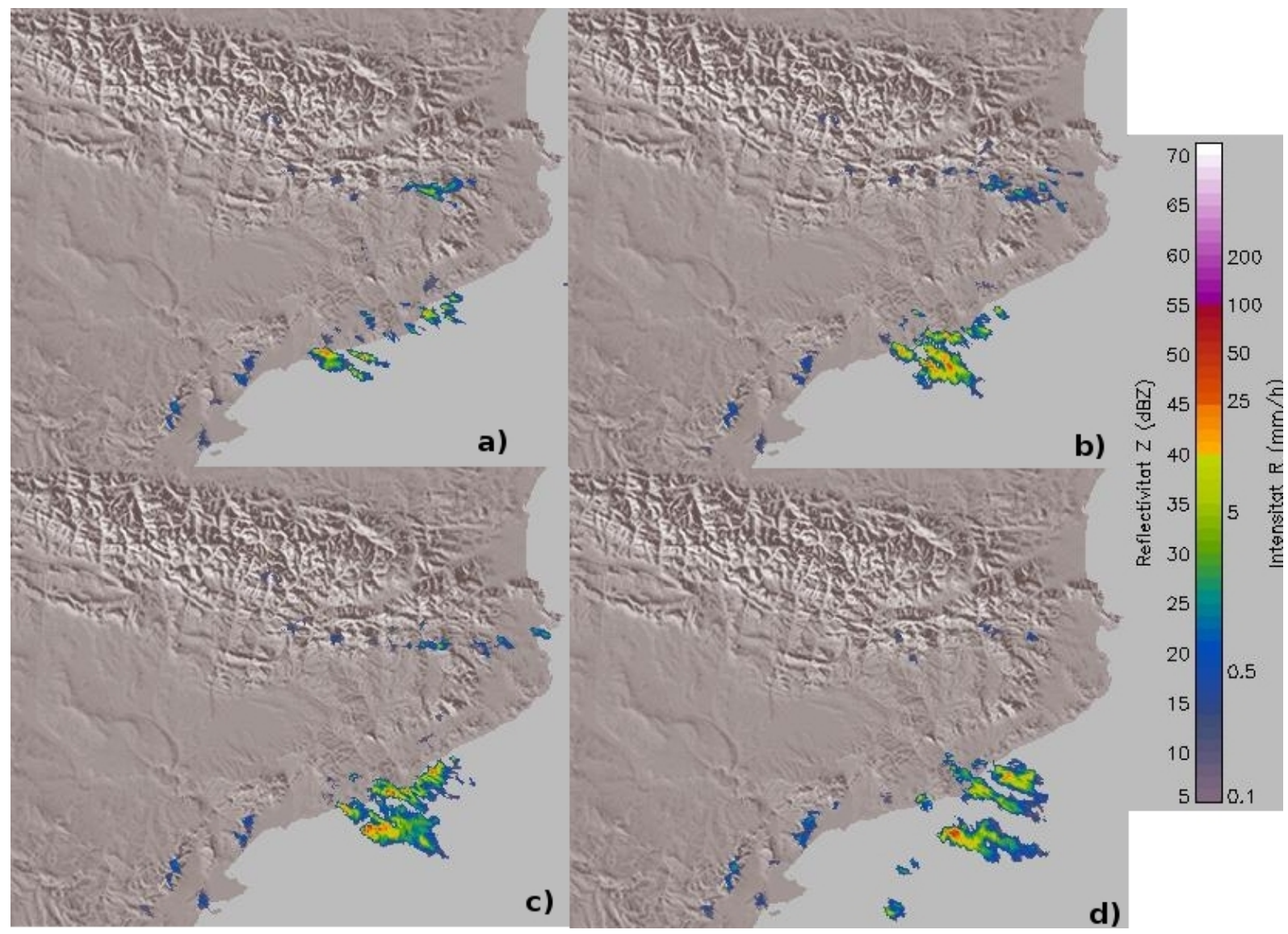

Figure 8. Radar reflectivity at (a) 23 UTC of day 2, (b) 00 UTC, (c) 00:20 UTC, and (d) 01:30 UTC of September 3rd 2000. Source: AEMet.

ographical region. A mesoscale model was used to simulate the atmospheric conditions of two episodes at the end of the summer on September 2nd 2000 and August 30th 2007. In both episodes, in addition to studying the characteristics of the atmosphere in the area of interest, the model outputs can be compared with the radar data of the Agencia Estatal de Meteorología (AEMet) (Spanish meteorological agency) and those of the Servei Meteorológic de Catalunya (Meteocat) (Meteorological Service of Catalonia) can be compared. Moreover, in the first case, on September 2nd 2000, the model output is compared with the observations made at the station in Viladecans, located in the Llobregat delta.

\subsection{Characteristics of the numerical simulation}

In order to do a more precise study of the phenomenon, a simulation with the version 3.4 of the fifth generation of the PennState/NCAR mesoscale model, named MM5 (Dudhia, 1993, Grell et al., 1995). This model was recently used in other studies of coastal fronts (Malda et al., 2007). The initial and boundary conditions were obtained from the global analysis of the model of the European Centre for MediumRange Weather Forecasts (ECMWF); in the numerical simulation these conditions are updated every six hours.
Four nested domains with horizontal resolutions of 27 ,

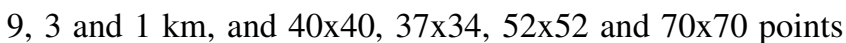
respectively (see Figure 7 ) have been defined. The central point of the larger domain is located at $41.99^{\circ} \mathrm{N}, 2.07^{\circ} \mathrm{E}$. The simulations were carried out with the option 2-way nesting in all domains. A high horizontal resolution in the smaller domain is necessary in order to capture the surface winds that descend the Llobregat valley and nearby mountains. Although a high resolution would also be advisable in the vertical direction, if the goal is to capture the appearance of a possible low level jet in the valley, only 27 vertical levels $\sigma\left(\sigma=\left(p-p_{\text {top }}\right) /\left(p_{s f c}-p_{\text {top }}\right)\right)$, where $p_{s f c}$ is the surface pressure and $p_{t o p}$ is the pressure at the top of the model $(100 \mathrm{hPa})$, given that this is not the goal of the work. Even so, in the planetary boundary layer the vertical resolution is higher in order to attempt to capture the rising of the air during the formation of the front. The four lowest levels of the numeric simulation are approximately at $0,170,210,260 \mathrm{~m}$ above the ground. Due to the dependence of the $\sigma$ levels with pressure, the height where these levels are found could have variations in relation to the time or point of the model.

In all four domains the MRF parameterization has been used for the boundary layer (Troen and Mahrt, 1986; Hong 

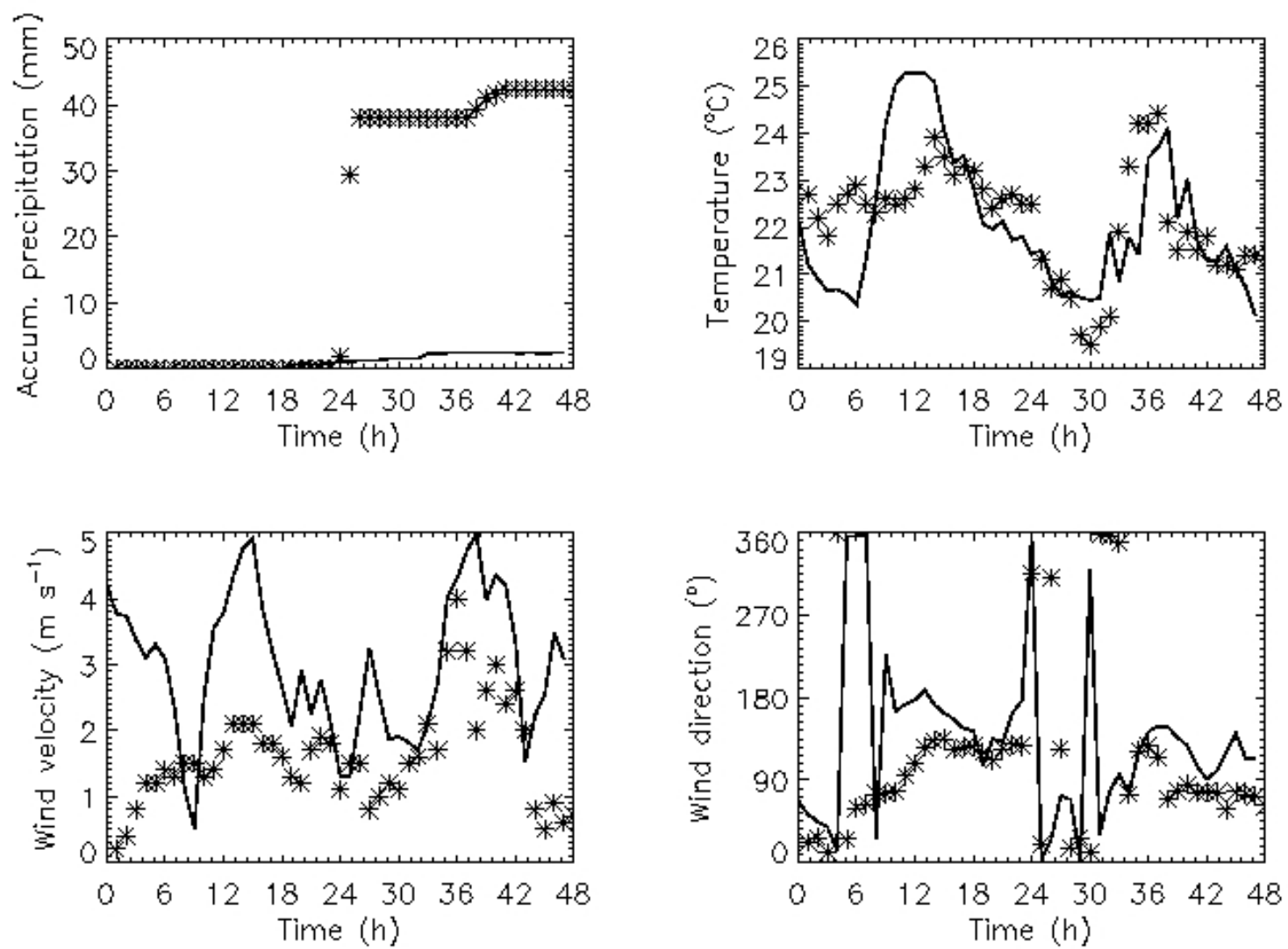

Figure 9. Temporal evolution from 00 UTC on September 2nd to 00 UTC on September 4th 2000 of the accumulated precipitation, wind direction and intensity, and temperature observed at the Viladecans station (asterisks) and obtained with the MM5 model from the model point -in the domain at $1 \mathrm{~km}$ resolution- closer to the station (solid line).

and Pan, 1996), "simple ice" (Dudhia, 1989) as humidity diagram, and "cloud" as atmospheric radiation diagram. The convection diagram has been different in the two larger domains and in the two smaller ones. The Kain-Fritsch parameterization (Fritsch and Chappell, 1980; Kain and Fritsch, 1993; Kain and Fritsch, 2004), has been used in the two larger domains, and a convection diagram has not been used in the smaller ones as advised by the resolution of the grid mesh.

\subsection{Simulations of episodes}

Below two episodes are modelled assuming that precipitation is caused by the formation of a coastal front on the Llobregat delta.

\subsubsection{September 2nd 2000}

That day there was low pressure in the south of Spain (not shown) that caused weak winds on surface that remained throughout all of day 3. The wind at the upper height was also not significant in the area of Catalonia.
The satellite images from September 2nd and 3rd showed clouds that were spread throughout the north of the peninsula and to the sea (not shown). Those clouds got colder and got more moisture content during the early hours of day 3, especially in the area of study. On the other hand, the radar images show that there were no rains until the last hours of the 2nd of September, when an important band of precipitation parallel to the coast appeared (see Figure 8). This fact could be a sign of the presence of a coastal front. The precipitation moved to the sea, where it became intensified.

Before presenting how the model reproduces the meteorological situation on a mesoscalar scale and the fundamental mechanisms for the development of the surface mesoscalar front in front of the Llobregat delta, we will compare the model output with the data obtained during the episode in the automatic station in Viladecans.

Figure 9 shows the temporal evolution during the second and third days of September of the precipitation accumulated, the temperature at $2 \mathrm{~m}$, the wind direction and intensity at $10 \mathrm{~m}$ observed at the station (asterisks) and simulated with the mesoscale from the model point -at $1 \mathrm{~km}$ horizontal resolution- closer to the station (solid line). 

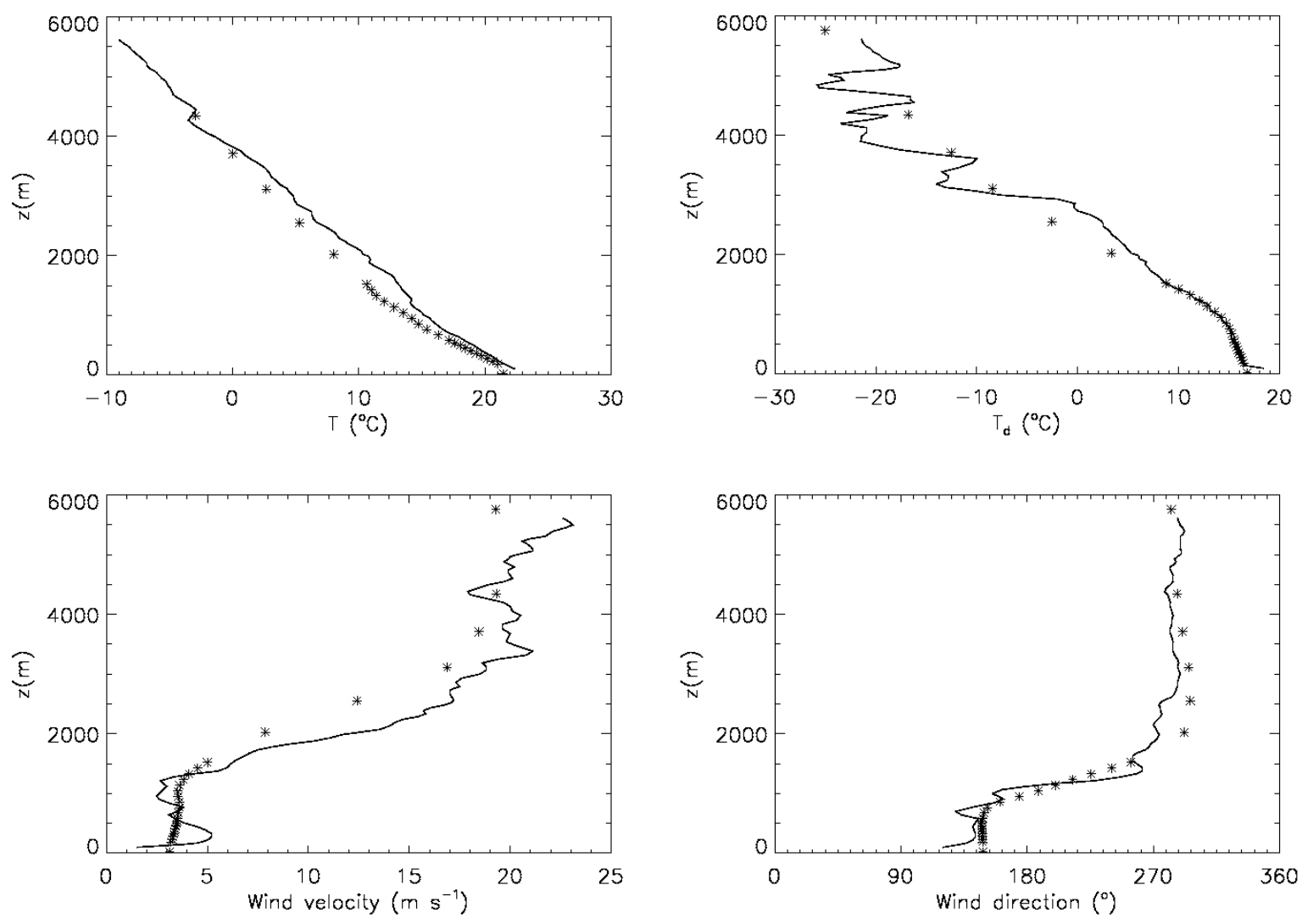

Figure 10. Vertical profiles of temperature, temperature in the frost point, wind velocity and direction measured with the Barcelona sounding (solid line) and obtained in the nearest point of the MM5 model (asterisks) on September 3rd 2000 at 00 UTC.

As shown in the figure, the model clearly underestimates the precipitation collected in the station. Moreover, the model simulates more precipitation between 10 UTC and 18 UTC on day 3 and not during the previous night.

Regarding temperature, the model adjusts the observations made during the early morning of day 3 quite well, with a $5 \%$ of maximum error. Likewise, the model correctly simulates the wind direction and intensity observed during the last hours of day 2 and throughout day 3. This period coincides with the development of the front. As shown, winds between 00 UTC and 08 UTC on September 3rd come from the northwest, and could be drainage winds that descend the Llobregat valley. Therefore, looking at Figure 9, the model correctly reproduces the atmospheric conditions registered at Viladecans, except the precipitation which, as postulated throughout the article, is quite a local phenomenon.

The sounding in Barcelona, $15 \mathrm{~km}$ to the north of the area of study, and outside the influence of the Llobregat delta, provides another source of validation of the model for the days of study. Figure 10 represents the vertical profiles of the temperature, the temperature of the dew point, the wind direction and intensity measured with the Barcelona sounding $\left(41.383^{\circ} \mathrm{N}, 2.116^{\circ} \mathrm{E}\right)$ and obtained with the model MM5 from the point in domain 4 closer to the sounding point $\left(41.404^{\circ} \mathrm{N}, 2.181^{\circ} \mathrm{E}, 28 \mathrm{~m}\right)$ on September 3rd 2000 at 00 UTC.

We can conclude that, despite the fact that the model can not capture all the structure of the surface layer, especially regarding wind speed, the atmospheric conditions in the boundary layer are well reproduced on the day of study.

Next, we will focus on the wind simulation and precipitation obtained in the two smaller domains, of 3 and $1 \mathrm{~km}$ horizontal resolution. Figure 11 shows the divergence (negative convergence) obtained with the numeric simulation in domain 3 between 00 and 05 UTC on September 3rd 2000. As illustrated, the model produces negative values of the divergence, i.e., positive convergence, in the entire coast before the Llobregat delta, which favors vertical movements and could produce cloudiness in the area. To observe how this convergence happens and its effects in more detail, we will analyze the model output to the smaller domain.

Figure 12 shows surface winds and the accumulated precipitation obtained with the model in the smallest domain of the simulation between 00 and 05 UTC on September 3rd 2000. It can be observed that initially the predominant winds 

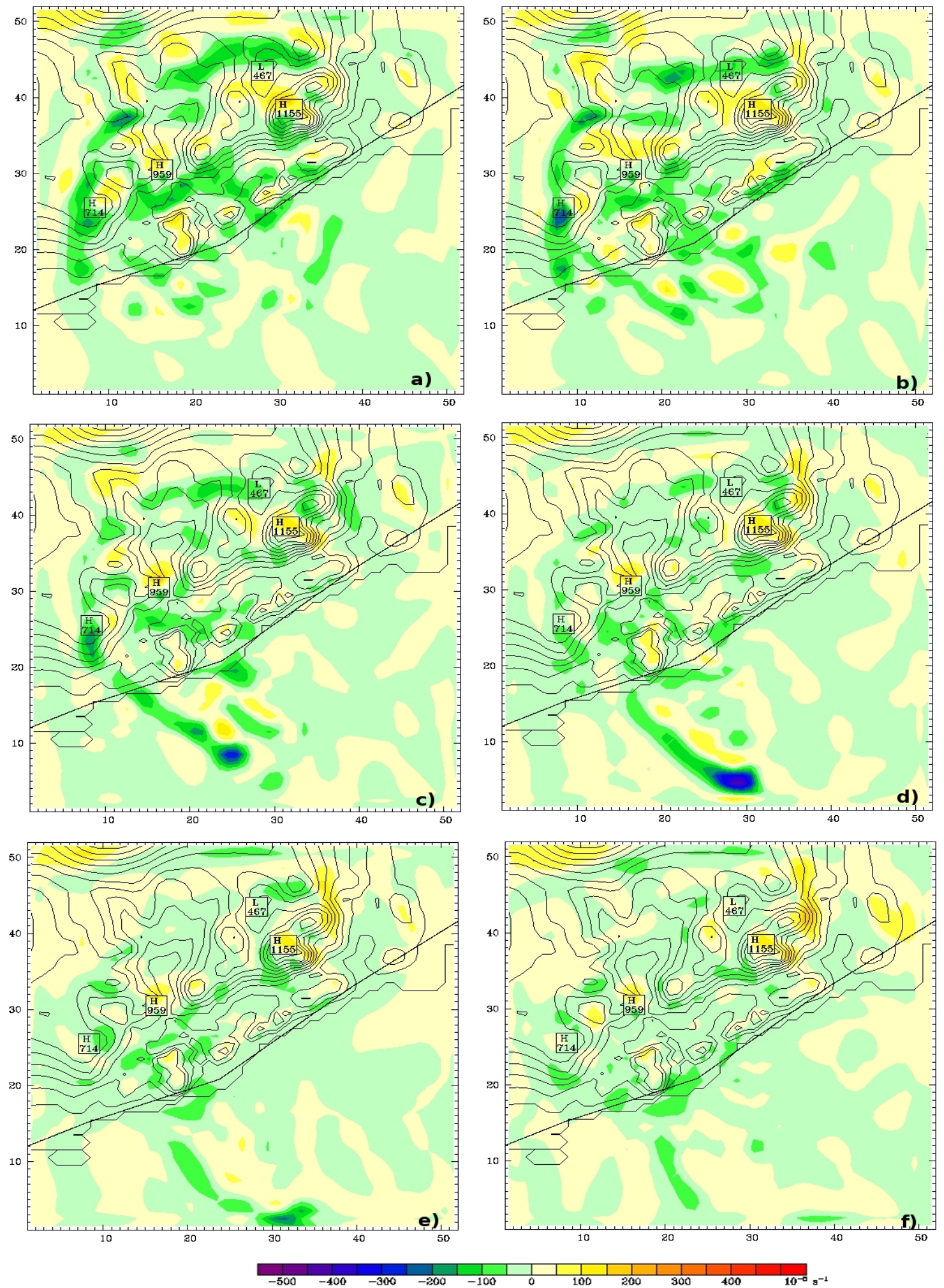

Figure 11. Hourly divergence (negative convergence) obtained with the MM5 from the model point -in the domain at $3 \mathrm{~km}$ resolutionevery hour between (a) 00 and (f) 05 UTC on September 3rd 2000. 

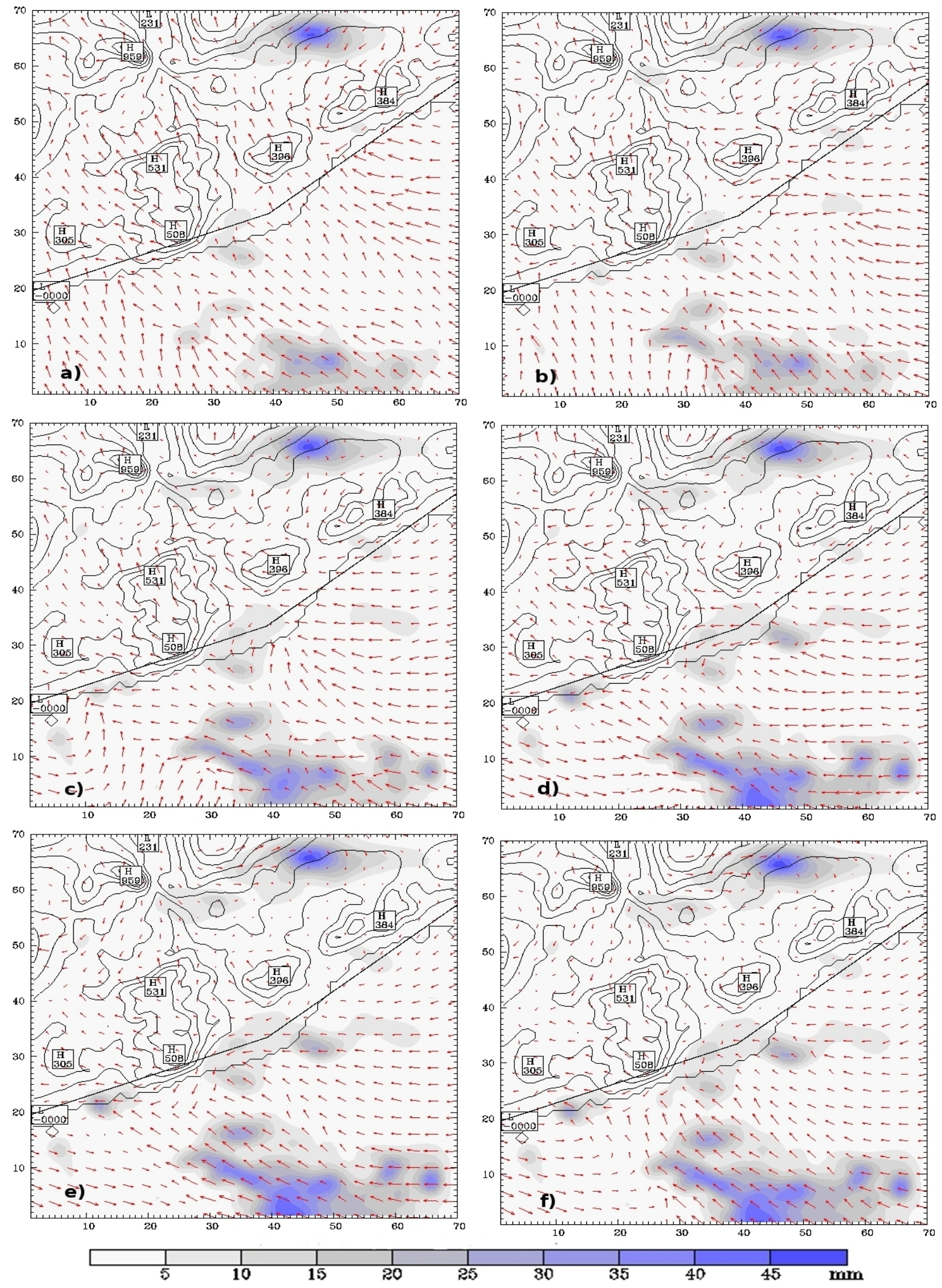

Figure 12. Surface winds (red arrows) and accumulated precipitation outlines obtained with the MM5 from the model point -in the domain at $1 \mathrm{~km}$ resolution- every hour between (a) 00 and (f) 05 UTC on September 3rd 2000. 

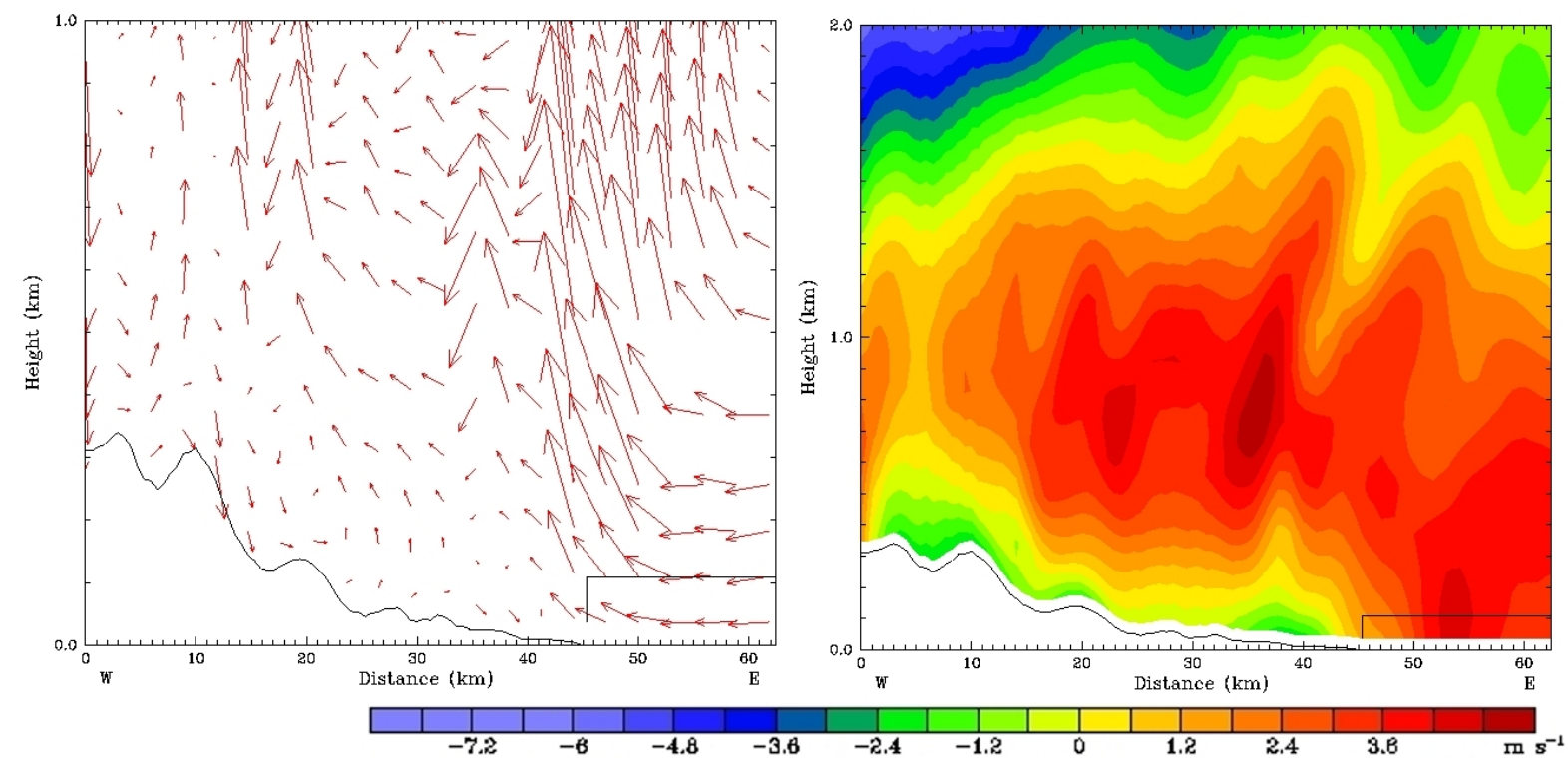

Figure 13. Wind field (left) and intensity of the horizontal component of the wind in north-south direction (right) at 06 UTC on September 3rd 2000 along the vertical cut marked with a red line in Figure 15. It is important to remark that the vertical scale is different in both graphs. In the graph on the left the maximum horizontal and vertical magnitudes of the wind are $5.6 \mathrm{~m} \mathrm{~s}^{-1}$ and $47.6 \mathrm{~cm} \mathrm{~s}^{-1}$ respectively.

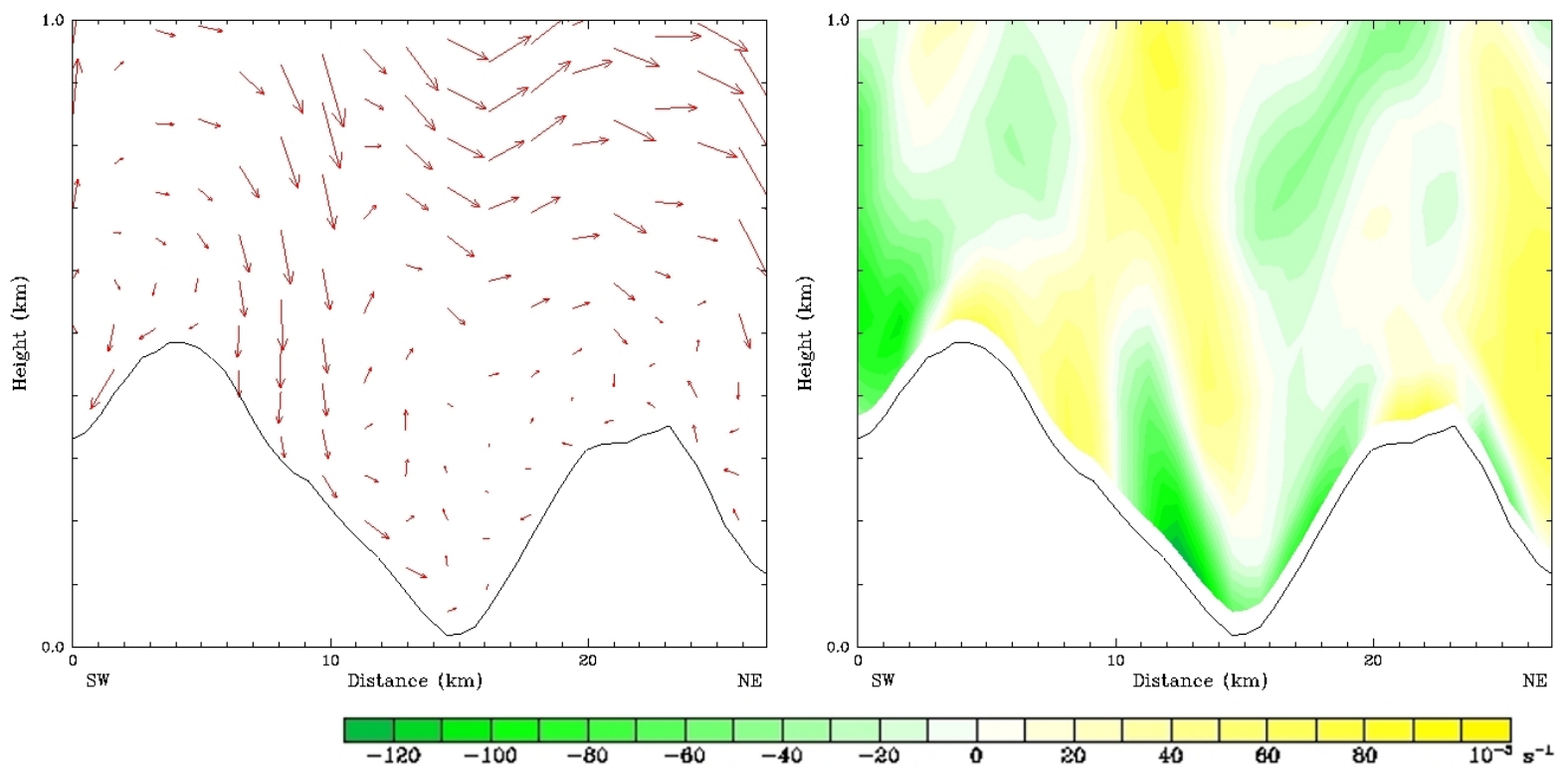

Figure 14. Wind field (left) and divergence (right) at 06 UTC on September 3rd 2000 along the vertical cut marked with a black line in Figure 3. In the graph on the left the maximum horizontal and vertical magnitudes of the wind are $5.2 \mathrm{~m} \mathrm{~s}^{-1}$ and $35.2 \mathrm{~cm} \mathrm{~s}^{-1}$ respectively. 

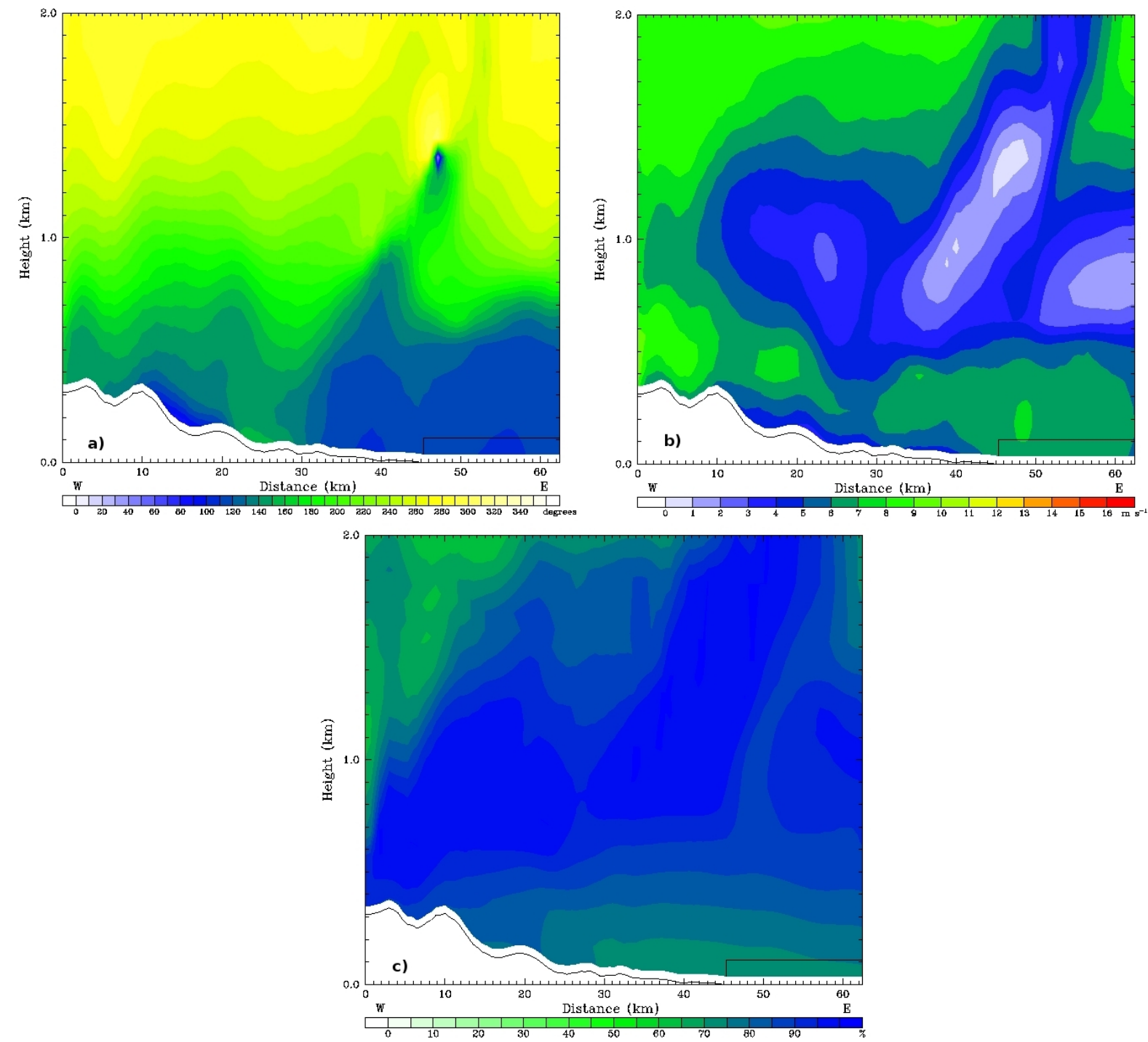

Figure 15. (a) Direction, (b) intensity of the wind and (c) relative humidity in relation to the obtained height with the model MM5 at 20 UTC on September 2nd 2000 for a longitudinal cut in the Llobregat valley (red line in Figure 3).

in the valley are from the southeast, which are probably produced by the seabreeze. But, as the night progresses, the synoptic winds from the southeast compete with the drainage winds coming from the Llobregat valley in the northwest direction, and a convergence area along the coast appears, as shown in Figure 11. Therefore, as mentioned above, the relatively dryer and colder air that descends along the valley can have an important role in the development of the front.

Regarding precipitation, as mentioned before, the model does not adequately predict the precipitation in the area. If we compare with the images of the radar (see Figure 8), it becomes clear that the model produces precipitation further away from the coastline. This fact could be due to the overestimation of the intensity of the northwesterly wind shown in Figure 9. Even so, the quantities of accumulated precipitation in the model are similar to those collected in the station in Viladecans.

Figure 13 shows the wind field (left) and the horizontal component of the wind in the north-south direction (right) along a longitudinal cut that follows the valley (red line in Figure 3).

In the wind field shown in Figure 13, the convergence of air produced in the delta between the winds that descend the valley and those coming from the sea is clearly visible. If we pay attention to the figure where the north-south component of the horizontal velocity is shown, we can observe how, at this time, surface winds on the coast are positive, that is to say, in a northerly direction, and change sign as we move up the valley.

To get a clearer observation of the drainage winds that meet along the valley from the nearby mountains, we 


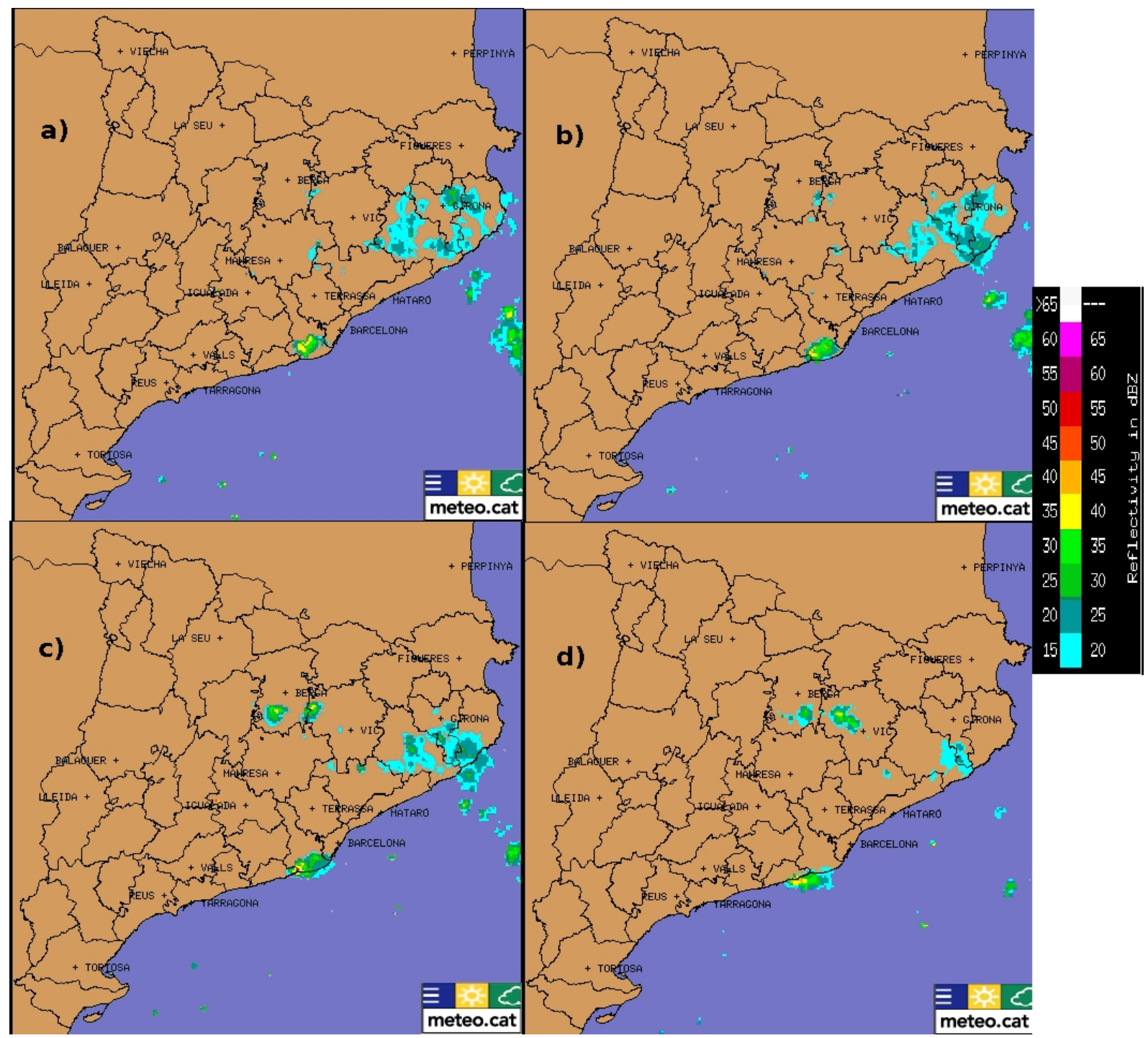

Figure 16. Radar reflectivity at (a) 20:48 UTC, (b) 21 UTC, (c) 21:12 UTC and (d) 21:36 UTC on August 30th 2007. Source: Meteocat.

will study the wind regime and the convergence of the air along the transversal cut shown in Figure 3 (black line). Figure 14 shows the wind regime and the divergence along the transversal cut marked in black in Figure 3, at 06 UTC on September 3rd 2000.

The figure shows the winds that descend from the mountainsides and meet in the valley (negative divergence). This cold and dry air flow descends along the valley during the night, meeting with the moister, warmer sea air, which causes the formation of a front.

In order to estimate the height of this front, Figure 15 shows the variation with the height of the direction and intensity of the wind and relative humidity at 20 UTC on September 2nd 2000, along the Llobregat valley. As we can see, there are clearly two different kinds of flows. On the surface the air is dry; it comes from the southeast and has a moderate speed. These conditions remain stable until approximately $500 \mathrm{~m}$. Above this height, the air is moister, its speed is reduced and its direction turns south. Finally, at the heights above $1000 \mathrm{~m}$, the air speed increases again, the humidity decreases and it comes from the west. Therefore, the height of the front would be around $1000 \mathrm{~m}$.

\subsubsection{August 30th 2007}

From the radar images (Figure 16) we can observe the formation of precipitation over the Llobregat delta, which begins suddenly around 20:30 UTC and remains stationary for over an hour, until it moves to sea and the neighboring area of Garraf.

The modeling of this episode is shown in Figures 17 to 21. In Figure 17 we can observe how winds were initially of a sea component. Later, those winds interact with drainage winds from the low Llobregat valley, causing a surface cold front that generates the precipitation. Precipitation was up to 

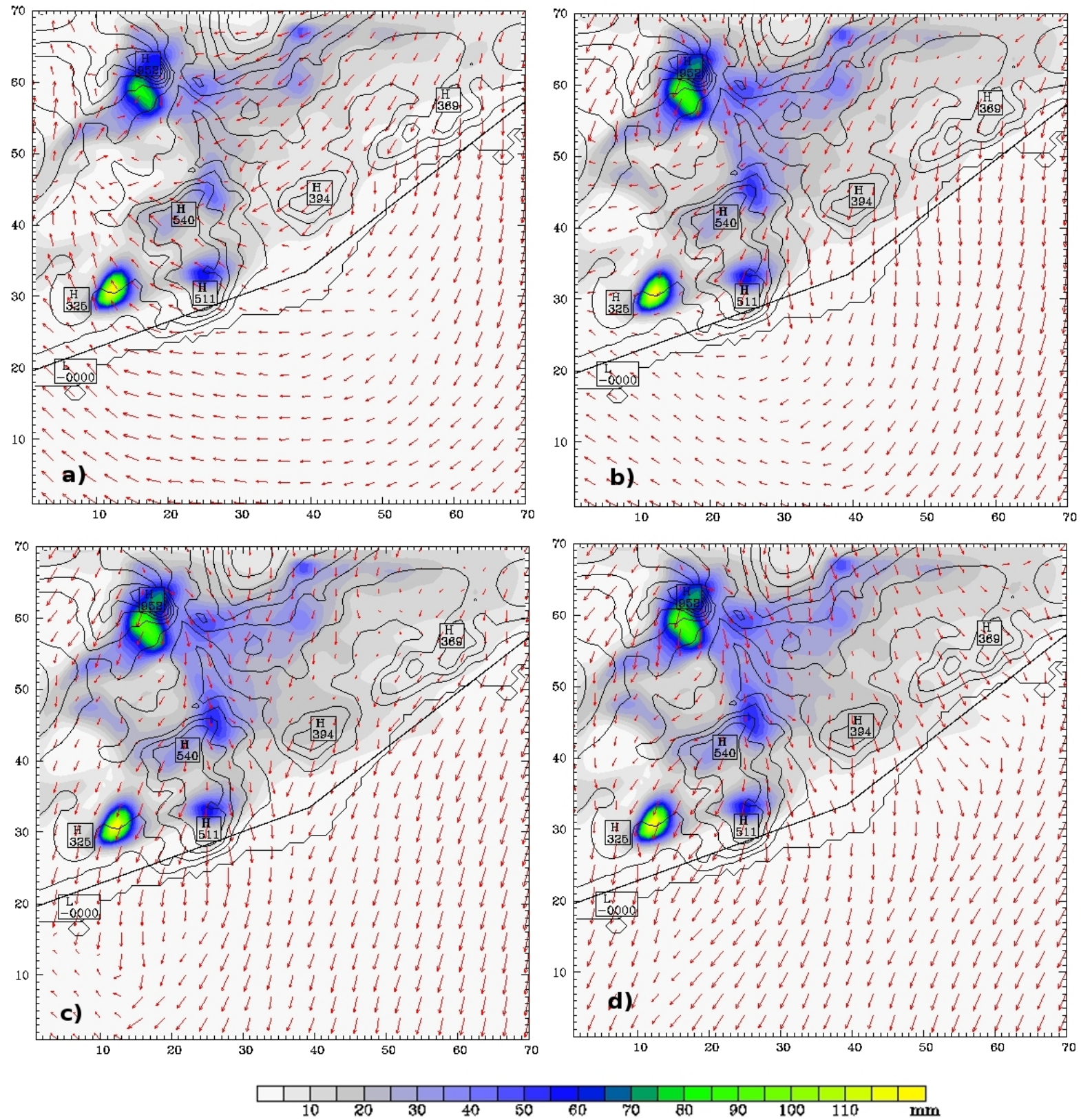

Figure 17. Images of the surface wind and accumulated precipitation obtained with the MM5 from the model point -in the domain at $1 \mathrm{~km}$ resolution- at (a) 19 UTC, (b) 20 UTC, (c) 21 UTC and (d) 22 UTC on August 30th 2007.

$10 \mathrm{~mm}$ in the municipality of Viladecans. Around $22 \mathrm{UTC}$ the drainage wind dominates on the ground, and the cold air mass moves to the south when arriving to the delta coast. The front then moves to the Garraf coast, as observed in the radar images (Figure 16).

As for the accumulated precipitation, the comparison with the radar images highlights that the model does not properly reproduce its spatial location. The precipitation prescribed by the model is located more inland and directed to the south, over the Garraf massif and Ordal (see Figure 17), than the one observed in the radar images (Figure 16).
Figures 18, 19 and 20 show, respectively, the variation with the height of the direction, wind intensity and relative humidity obtained along the Llobregat valley (red line in Figure 3) during the evening of August 30th 2007. The existence of a surface front should be reflected by a, more or less, noticeable variation in relation to the height of the direction and, perhaps, intensity, as well as relative humidity.

In Figure 18 we can observe how the wind direction progressively changes with the height along the whole valley, from 19 UTC. This shear becomes more marked from 20 UTC, corresponding to the formation of the precipitation, 

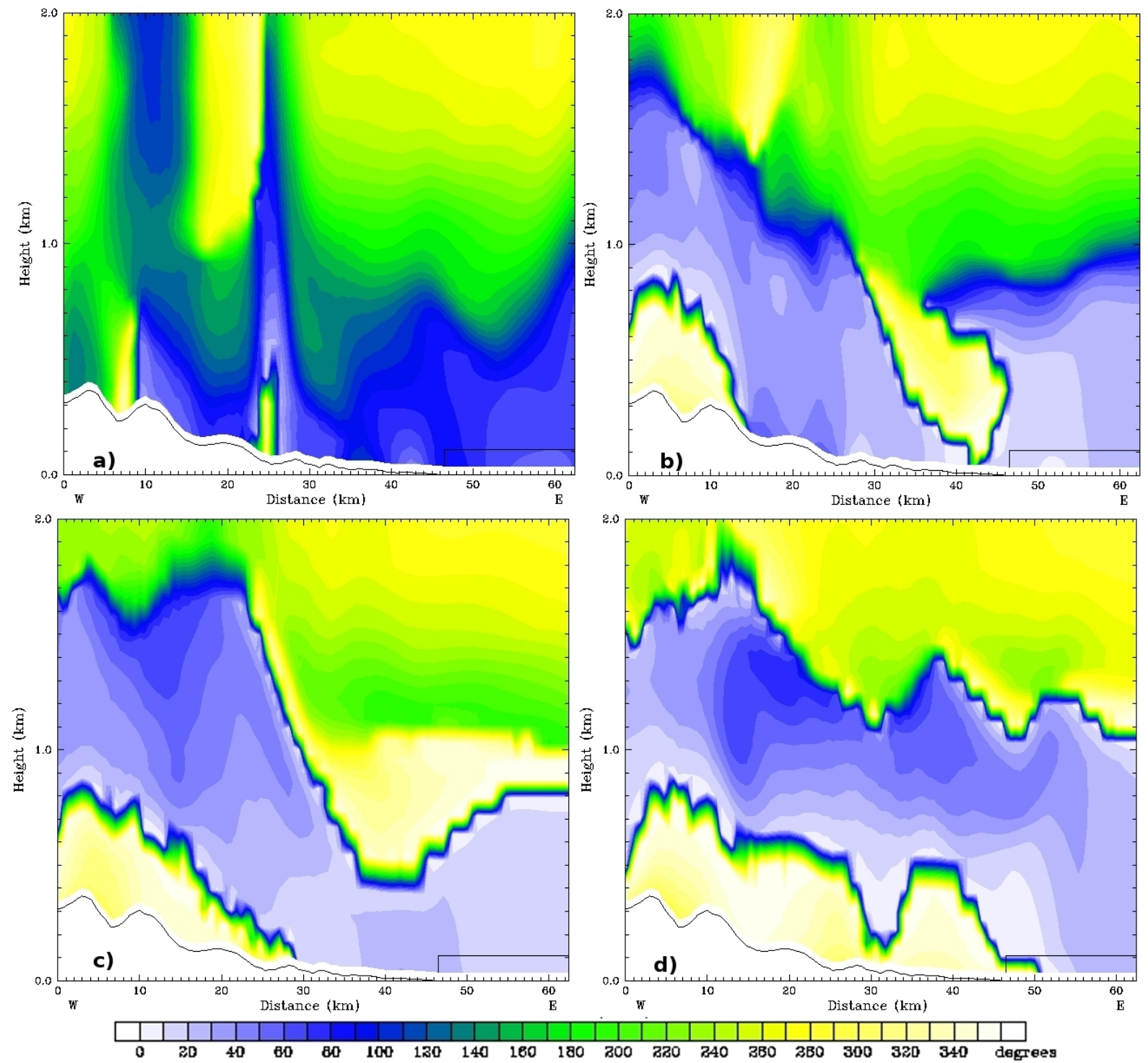

Figure 18. Wind direction in relation to height obtained with the MM5 model on August 30th 2007 along the Llobregat valley (red line in Figure 3) at (a) 19 UTC, (b) 20 UTC, (c) 21 UTC and (d) 22 UTC.

according to the radar images (Figure 16). While on the surface the wind has a north component, coming from the drainage of the Llobregat valley, at upper levels the wind changes more or less abruptly depending on the time, to a south and southwest component. The height of this change in the direction of the wind, that follows the valley topography, is located around $900 \mathrm{~m}$, an height that would determine the height of the surface front in this episode.

The intensity of the wind shows the appearance of a maximum at low levels in the area of interest (see Figure 19). As we can see, from 20 UTC, surface winds are very important, and they decrease with height until they get to the limit of the front, slightly under $1000 \mathrm{~m}$. It is important to stress the correspondance between the variation with the height of the wind direction and intensity showed in Figures 18 and 19.

To confirm the existence of two air masses of different characteristics, Figure 20 shows the variation of relative humidity with the height along the Llobregat valley during the night of August 30th 2007. Again, it is important to stress the correlation between humidity and wind intensity/direction from 20 UTC. Initially, the vertical gradient of humidity is very small along the valley (Figure 20a). But as time passes, humidity at higher heights increases, as sea winds move upward over drainage winds, which are colder and less moist. This produces, from 21 UTC, a vertical gradient of moisture typical of a cold front: the air on the surface keeps a humidity on the order of $60 \%$, while increasing at higher heights, until it reaches saturation near 

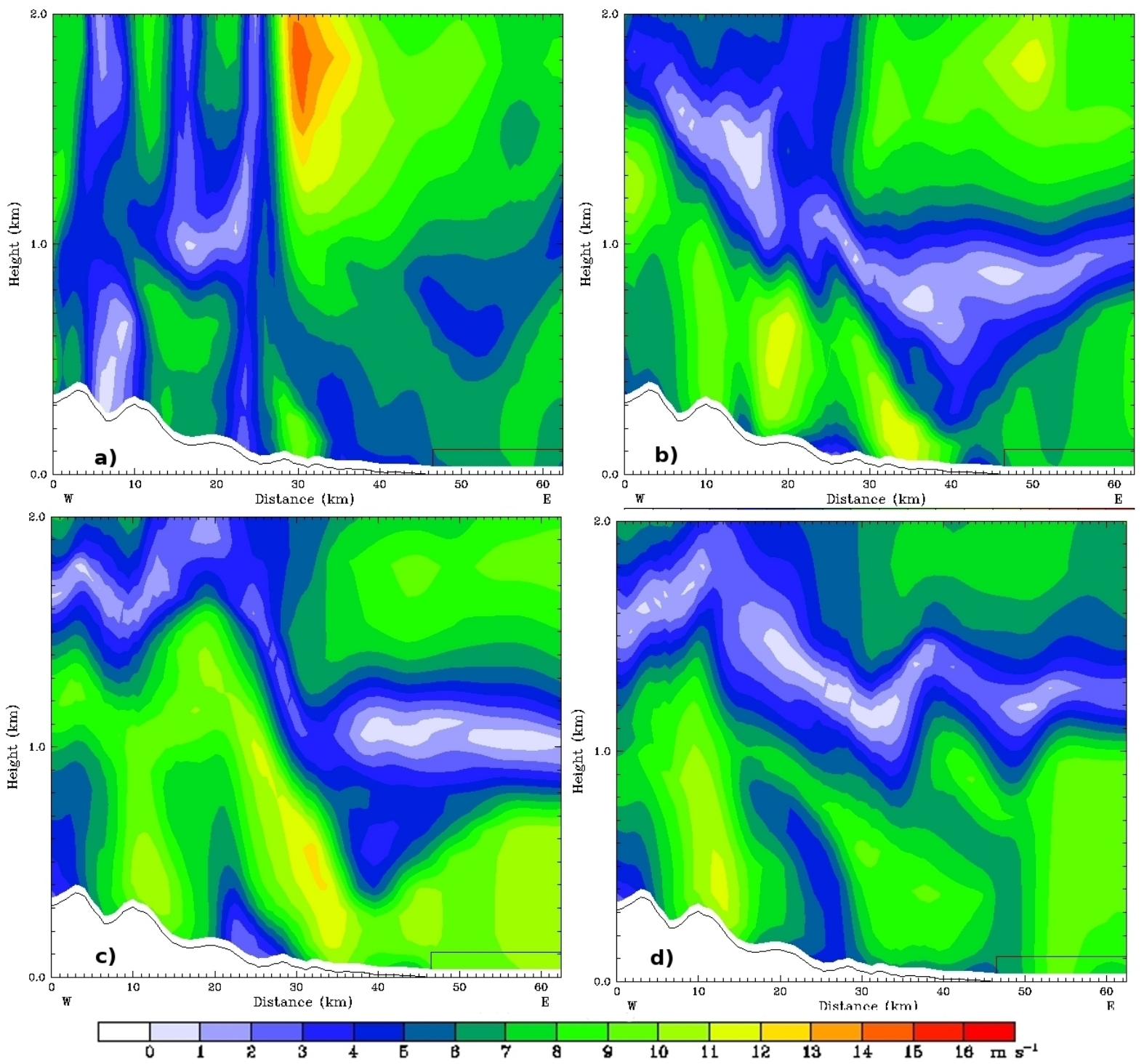

Figure 19. Wind intensity in relation to height obtained with the MM5 model on August 30th 2007 along the Llobregat valley (red line in Figure 3) at (a) 19 UTC, (b) 20 UTC, (c) 21 UTC and (d) 22 UTC.

$900 \mathrm{~m}$, coinciding with the change in the wind direction and to the minimum of intensity, what we suppose is the height of the front.

The structure of the front can also be clearly observed in Figure 21, where wind direction and intensity, and relative humidity are represented along a cut perpendicular to the valley at 22 UTC on August 30th 2003. For all the variables represented in this figure the height of the front remains clearly marked by its vertical gradient.

\section{Conclusions}

After the analysis of the pluviometric regime in several stations located in the Llobregat delta and its environs, it has been shown how, despite proximity between the pluviometric stations, the annual average precipitation is higher in the area of the Llobregat delta in relation with the surrounding areas. This difference becomes more notable in relation with the stations located to the southwest, on the other side of the Garraf massif.

These differences are more noticeable in the fall than during the other seasons. In the pluviometric observatories of the delta environment, in general, rainfall during the fall is the most considerable of the year, but it does not reach, in general terms, the level of precipitation of the Llobregat delta, except in Begues, located above $400 \mathrm{~m}$. The reason presented in this work to explain the differences in precipitation is the formation of a nocturnal surface cold front in the delta or out to sea.

The Llobregat valley, wide and rectilinear in its last stretch, channels the nocturnal cold air in the end of the summer and fall, creating a cold front when arriving to the delta; it is dominated by a warm and moist air mass, a Mediter- 

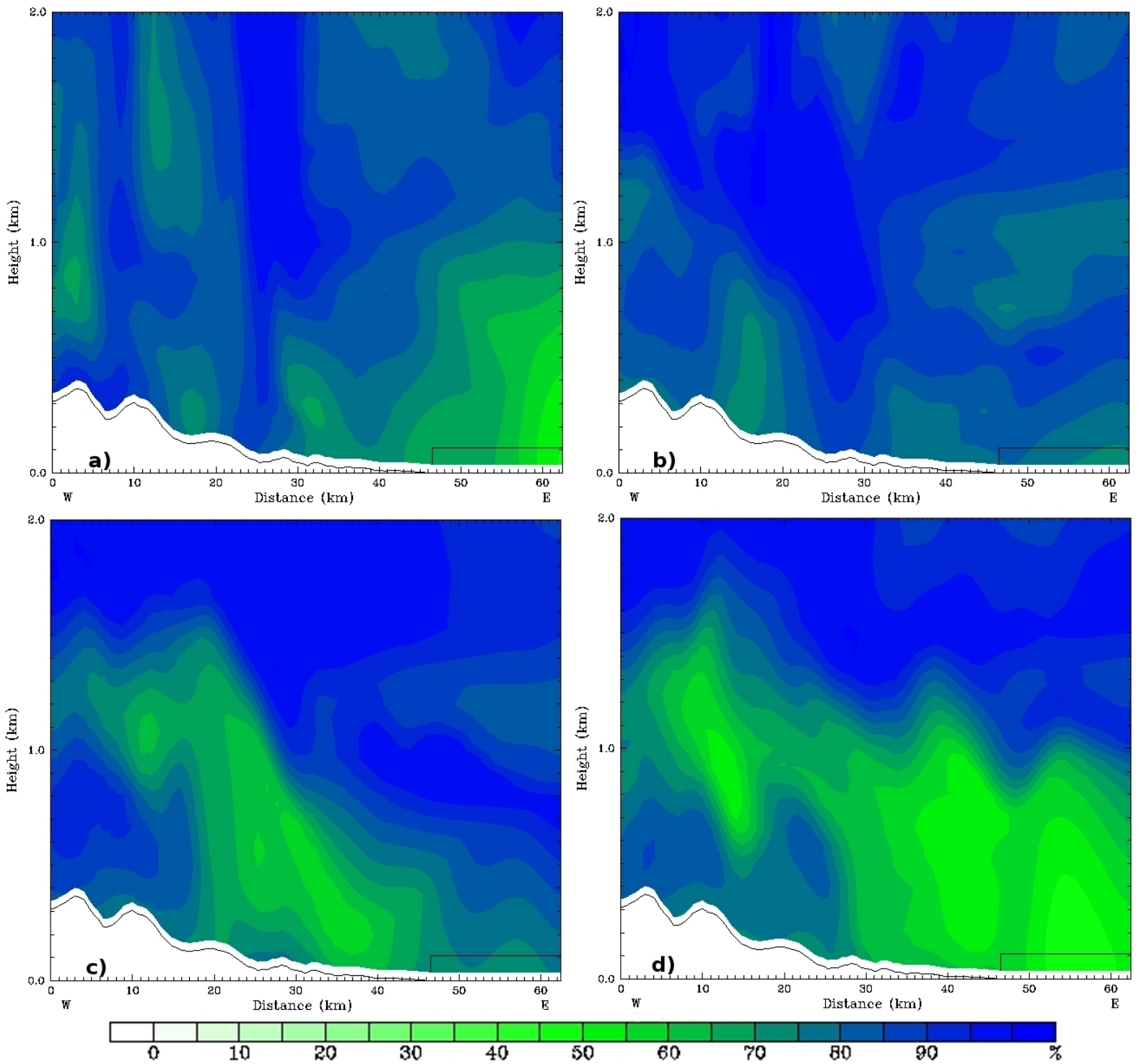

Figure 20. Relative humidity in relation to height obtained with the MM5 model on August 30th 2007 along the Llobregat valley (red line in Figure 3) at (a) 19 UTC, (b) 20 UTC, (c) 21 UTC and (d) 22 UTC.

ranean air mass. This front can generate cloudiness of vertical development, and provides significant precipitation out to sea, or precipitation that very often affects the delta area. This hypothesis is reinforced after analyzing the precipitation in the fall in the delta during the period 1993-2005, where we could observe that more than the $80 \%$ of it happened at night.

The situation is not the same for inland areas, such as Ordal or Collserola, or on the other side of the Garraf massif. The reason for this is that the Garraf massif prevents this front from spreading to the southeast, to the Garraf and Baix Penedès regions. As a consequence, in this area precipitation is noticeably lower in the fall, and during the rest of the year. It has been postulated that this air convergence in the area of the Llobregat delta might favor the formation of phenomena of deep convection and storms such as those described by Bech et al. (2007).
To confirm this fact, two meteorological situations were analyzed and simulated through the mesoscale model MM5, where everything indicates that this nocturnal surface cold front was generated and left precipitation in the Llobregat delta. The model simulates, in general terms, the synoptic situation, and clearly reproduces the drainage winds that appear at the end of the night in the Llobregat valley and cause the formation of a front in the area of the Llobregat delta.

On the two days presented, despite the fact that the simulation produces precipitation in the area of study, it is developed further away from the coast than observed in the radar images. This is also reflected in the comparison with the data from the Viladecans station for September 2nd 2000. The model properly simulates the wind direction and temperature during the night of the 2 nd and early morning of 

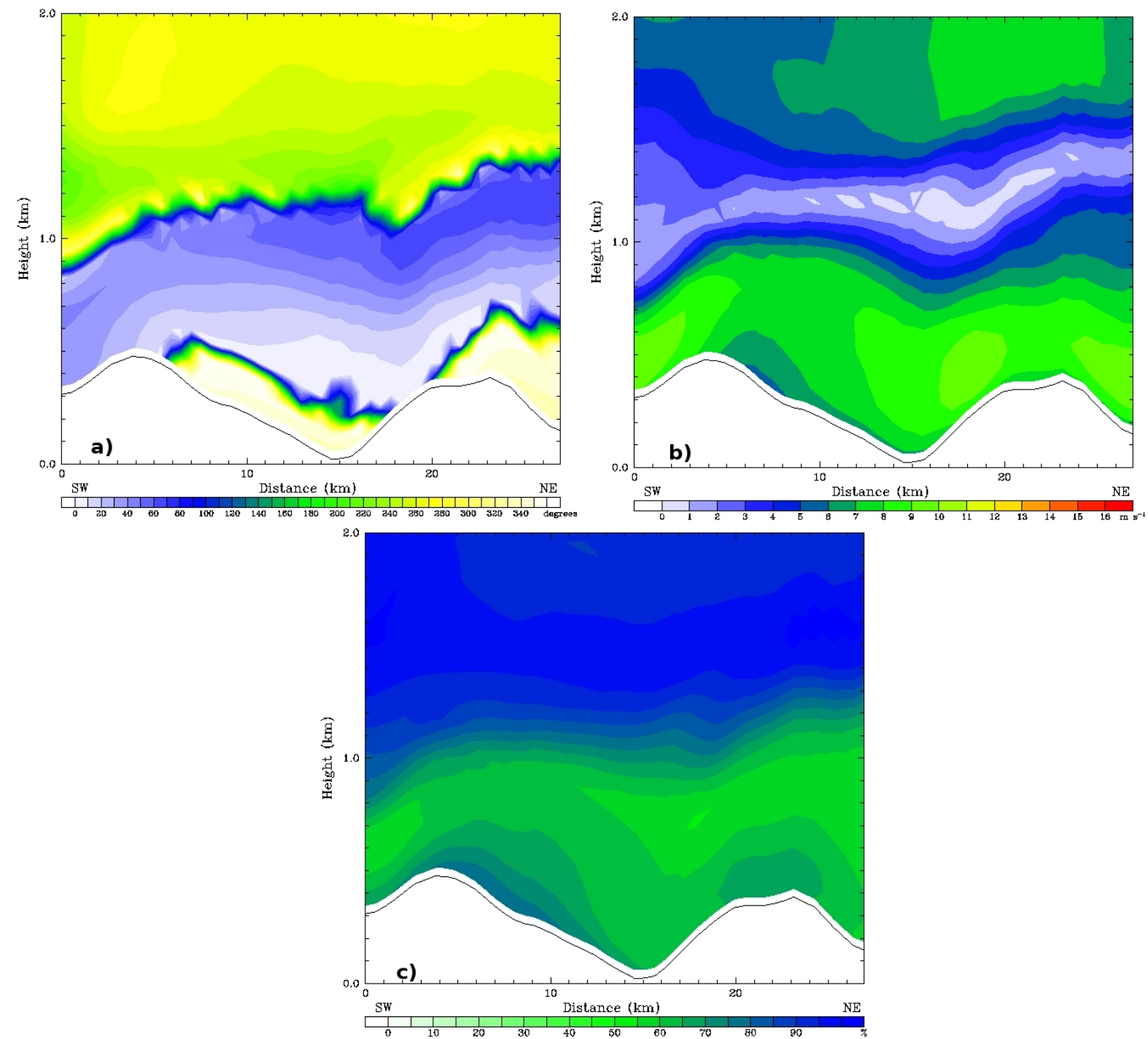

Figure 21. (a) Direction, (b) intensity of the wind and (c) relative humidity in relation to height obtained with the MM5 model at 22 UTC on August 30th 2007 in a transversal cut of the Llobregat valley (black line in Figure 3).

the 3rd of September 2000 at this point. On the other hand, the model slightly overestimates the intensity of the wind. This fact could result in the area of simulated precipitation moving to sea, therefore underestimating the registered precipitation at Viladecans station.

The analysis of the flux structure along and perpendicular to the Llobregat valley has allowed us to characterize the front structure and estimate its height. The characteristics of the episodes presented in this work are similar to the ones analyzed by Herrero (2008) on October 10th and 25th 2007. The height of the front in all these works is similar to that presented in other previous works carried out in the eastern Mediterranean (Neumann, 1951) and is located around $1000 \mathrm{~m}$.

Therefore, in general, a pluviometric anomaly in the fall in the Llobregat delta could be caused by the appearance of a nocturnal surface front over the coast of the delta. The MM5 model has made it possible to simulate the appearance of drainage winds in the valley during an episode of intense rain over the area, which is essential for the formation of the front according to the hypothesis formulated in this work. In order to confirm it, it is necessary to make additional simulations of other episodes similar to the ones already identified.

Acknowledgements. The radar images and the data from the automatic stations have been provided by the Agencia Estatal de Meteorología and the Servei Meteorològic de Catalunya. This research has been partly carried out with the resources of the Centre de Supercomputació de Catalunya. D. Pino's research has been partly financed by the project SGR-2004 of the Generalitat de Catalunya.

\section{References}

Bech, J., Pascual, R., Rigó, T., Pineda, N., López, J. M., Arús, J., and Gayà, M., 2007: An observational study of the 7th September 
2005 Barcelona tornado outbreak, Nat Hazards Earth Syst Sci, 7, 139.

Bolle, J. H., 2002: Climate, climate variability and impacts in the Mediterranean area: An overview, Springer Ed., Mediterranean Climate, 320 pag.

Callado, A. and Pascual, R., 2002: Storms in front of the mounth in north-eastern coast of Iberian penninsula, Proceedings del 4th Plinius Conference on Mediterranean Storms, Pollença (Espanya), 2-4 octubre.

Clavero, P., Martín-Vide, J., and Raso, J., 1996: Atlas climàtic de Catalunya: termopluviometria, Departament de Medi Ambient, Generalitat de Catalunya, 42 pag.

Dudhia, J., 1989: Numerical study of convection observed during the Winter Monsoon Experiment using a mesoscale twodimensional model, J Atmos Sci, 46, 3077-3107.

Dudhia, J., 1993: A nonhydrostatic version of the Penn-State-NCAR mesoscale model: validation tests and simulation o fan Atlantic cyclone and cold front, Mon Wea Rev, 121, 1493-1513.

Fontserè, E., 1959: La masa de aire mediterránea, Rev Geofis, 18 , 35-40.

Fritsch, J. M. and Chappell, C. F., 1980: Numerical prediction of convectively driven mesoscale pressure systems. Part I: Convective parameterization, J Atmos Sci, 37, 1722-1733.

Grell, G. A., Dudhia, J., and Stauffer, D. R., 1995: A description of the fifth-generation Penn State/NCAR Mesoscale Model (MM5), NCAR Tech, nCAR/TN-398+STR, 122 pag.

Herrero, V., 2008: Caracterització del front superficial del delta del Llobregat, Universitat Politècnica de Catalunya, projecte Final de Carrera.

Hong, S. Y. and Pan, H. L., 1996: Nonlocal boundary layer vertical diffusion in a medium-range forecast model, Mon Wea Rev, 124, 2322-2339.

Jansà, A., 1997: INM/WMO International Symposium on Cyclones and Hazardous Weather in the Mediterranean, A general view about Mediterranean Meteorology, Cyclones and Hazardous Weather (opening lecture), Palma de Mallorca (Spain), 14-17 abril. MMA-INM/UIB, 33-42.

Kain, J. S. and Fritsch, J. M., 1993: The Kain-Fritsch scheme. The representation of Cumulus convection in numerical models, Meteorol Monogr, 46, edited by: Emmanuel, K. A. and Raymond, D. J., Amer Meteorol Soc, 165-170.

Kain, J. S. and Fritsch, J. M., 2004: The Kain-Fritsch convective parameterization: an update, J Appl Meteorol, 43, 170-181.

Koch, S. E. and Ray, C. A., 1997: Mesoanalysis of summertime convergence zones in central and eastern North Carolina, Wea Forecast, 12, 56-77.

Malda, D., Vilà-Guerau de Arellano, J., van den Berg, W. D., and Zuurendonk, I. W., 2007: The role of atmospheric boundary layer-surface interactions on the development of coastal fronts, Ann Geophys, 25, 341-360.

Neumann, J., 1951: Land breezes and nocturnal thunderstorms, J Meteorol, 8, 60-67.

Pascual, R. and Callado, A., 2002: Mesoanalysis of recurrent convergence zones in northeastern Iberian Peninsula, Proceedings del 4th European Conference on Radar Meteorology (ERAD2002), Delft (Països Baixos), 18-22 Novembre. 59-64.

Troen, I. and Mahrt, L., 1986: A simple model of the atmospheric boundary layer: Sensitivity to surface evaporation, Bound Layer Meteorol, 37, 129-148.

von Neumann, J., 1941: Distribution of the ratio of the mean square successive difference to the variance, Ann Math Stat, 12, 367-
395.

Zhong, S. and Takle, E. S., 1992: An observational study of sea- and land-breeze circulation in an area of complex coastal heating, $\mathrm{J}$ Appl Meteorol, 31, 1226-1438. 